\title{
THE
}

\section{Baroclinic Transport Time Series of the Antarctic Circumpolar Current Measured in Drake Passage}

\author{
María Paz Chidichimo \\ Kathleen A. Donohue \\ University of Rhode Island, kdonohue@uri.edu \\ D. Randolph Watts \\ University of Rhode Island, randywatts@uri.edu \\ Karen L. Tracey
}

Follow this and additional works at: https://digitalcommons.uri.edu/gsofacpubs

Terms of Use

All rights reserved under copyright.

\section{Citation/Publisher Attribution \\ Chidichimo, Maria Paz; Donohue, Kathleen A; Watts, D Randolph; Tracey, Karen L. (2014). "Baroclinic Transport Time Series of the Antarctic Circumpolar Current Measured in Drake Passage." Journal of Physical Oceanography. 44(7): 1829-1853.}

Available at: http://dx.doi.org/10.1175/JPO-D-13-071.1

This Article is brought to you for free and open access by the Graduate School of Oceanography at DigitalCommons@URI. It has been accepted for inclusion in Graduate School of Oceanography Faculty Publications by an authorized administrator of DigitalCommons@URI. For more information, please contact digitalcommons-group@uri.edu. 


\title{
Baroclinic Transport Time Series of the Antarctic Circumpolar Current Measured in Drake Passage
}

\author{
María Paz Chidichimo,* Kathleen A. Donohue, D. Randolph Watts, and Karen L. Tracey \\ Graduate School of Oceanography, University of Rhode Island, Narragansett, Rhode Island
}

(Manuscript received 25 March 2013, in final form 5 March 2014)

\begin{abstract}
The first multiyear continuous time series of Antarctic Circumpolar Current (ACC) baroclinic transport through Drake Passage measured by moored observations is presented. From 2007 to 2011, 19 current- and pressure-recording inverted echo sounders and 3 current-meter moorings were deployed in Drake Passage to monitor the transport during the cDrake experiment. Full-depth ACC baroclinic transport relative to the bottom has a mean strength of $127.7 \pm 1.0$ Sverdrups $\left(\mathrm{Sv} ; 1 \mathrm{~Sv} \equiv 10^{6} \mathrm{~m}^{3} \mathrm{~s}^{-1}\right)$ with a standard deviation of $8.1 \mathrm{~Sv}$. Mean annual baroclinic transport is remarkably steady. About $65 \%$ of the baroclinic transport variance is associated with time periods shorter than 60 days with peaks at 20 and 55 days. Nearly $28 \%$ of apparent energy in the spectrum computed from transport subsampled at the 10-day repeat cycle of the Jason altimeter results from aliasing of high-frequency signals. Approximately $80 \%$ of the total baroclinic transport is carried by the Subantarctic Front and the Polar Front. Partitioning the baroclinic transport among neutral density $\gamma^{n}$ layers gives 39.2 Sv for Subantarctic Surface Water and Antarctic Intermediate Water $\left(\gamma^{n}<27.5 \mathrm{~kg} \mathrm{~m}^{-3}\right)$, 57.5 Sv for Upper Circumpolar Deep Water $\left(27.5<\gamma^{n}<28.0 \mathrm{~kg} \mathrm{~m}^{-3}\right)$, 27.7 Sv for Lower Circumpolar Deep Water $\left(28.0<\gamma^{n}<28.2 \mathrm{~kg} \mathrm{~m}^{-3}\right)$, and $3.3 \mathrm{~Sv}$ for Antarctic Bottom Water $\left(\gamma^{n}>28.2 \mathrm{~kg} \mathrm{~m}^{-3}\right)$. The transport standard deviation in these layers decreases with depth (4.0, 3.1, 2.1, and 1.1 Sv, respectively). The transport associated with each of these water masses is statistically steady. The ACC baroclinic transport exhibits considerable variability and is a major contributor to total ACC transport variability.
\end{abstract}

\section{Introduction}

The Antarctic Circumpolar Current (ACC) is a major current of the world's oceans. Because it connects the Atlantic, the Pacific, and the Indian Oceans in the Southern Hemisphere, the ACC plays a crucial role in the transfer of mass, heat, freshwater, and other properties among the three ocean basins. ACC transport variability is a key component for the climate system due to its role in the global-scale ocean circulation (Rintoul et al. 2010), and it is therefore an essential feature for modeling efforts to represent accurately. To date, however, the observations to quantify the ACC transport are sparse.

\footnotetext{
* Current affiliation: National Scientific and Technical Research Council (CONICET), Argentina.
}

Corresponding author address: María Paz Chidichimo, CONICET/ Departamento de Oceanografía, Servicio de Hidrografía Naval, Av. Montes de Oca 2124, C1270ABV, Buenos Aires, Argentina. E-mail: mpchidichimo@hidro.gov.ar
The International Southern Ocean Studies (ISOS) program took place between 1974 and 1981, providing valuable insights on the vertical and horizontal structure of the ACC in Drake Passage. Their measurements consisted of year-long mooring deployments of currentmeter moorings and pressure gauges across the passage together with hydrographic sections. The ACC flow was observed to be coincident with three narrow vertically coherent geostrophic jets with large eastward velocities associated with deep-reaching fronts (Nowlin et al. 1977). These fronts are, from north to south, the Subantarctic Front (SAF), Polar Front (PF), and Southern ACC Front (SACCF) (Orsi et al. 1995). More recently, from high-resolution hydrographic sections and maps of the gradient of sea surface height ( $\mathrm{SSH}$ ), a more complex structure of the ACC fronts than earlier coarser sampling suggested was found, with multiple filaments associated with each front merging and diverging along the circumpolar path (Sokolov and Rintoul 2007). In Drake Passage, as many as seven or eight frontal branches were observed at any one time (Sokolov and Rintoul 2009b). 




FIG. 1. (a) cDrake transport line and local dynamics array of CPIES (black triangles) and current-meter moorings (white circles). CPIES sites names on the transport line are displayed. Also shown is the WOCE SR1b repeat hydrographic line (black line). The mean positions of the ACC fronts from Orsi et al. (1995) are shown as thick gray lines. The slanting ridge of the SFZ is indicated. Bathymetry comes from Smith and Sandwell (1997). (b) Section of cDrake CPIES (black triangles) and current-meter moorings (white circles) and bathymetry along the transport line.

From the ISOS measurements, Whitworth (1983) and Whitworth and Peterson (1985) estimated the canonical value of the total transport of the ACC of 133.8 Sverdrups $\left(\mathrm{Sv} ; 1 \mathrm{~Sv} \equiv 10^{6} \mathrm{~m}^{3} \mathrm{~s}^{-1}\right)$ with a standard deviation of 11.2 Sv for a year-long record. Whitworth and Peterson (1985) constructed a time series of across-passage pressure difference measured at 500-m depth and termed this estimate "barotropic" transport variability. Because total transport was highly correlated to barotropic transport, they concluded that total transport variability on short time scales (seasonal and shorter) is mainly barotropic, implying that ACC transport could therefore be monitored using across-passage bottom pressure differences. Since 1993, the baroclinic component of ACC transport has been monitored from annually repeated hydrographic surveys along the World Ocean Circulation Experiment (WOCE)/Climate Variability and Predictability (CLIVAR) SR1b line between Burwood Bank and Elephant Island (see Fig. 1a). Cunningham et al. (2003) found that the average ACC baroclinic transport relative to zero at the deepest common level was $136.7 \mathrm{~Sv}$ with a standard deviation of $7.8 \mathrm{~Sv}$ between 1993 and 2000.

Cunningham et al. (2003) revisited the ISOS results in order to interpret the ISOS and hydrographic transports within a consistent baroclinic and barotropic framework. Specifically, baroclinic referred to geostrophic transports relative to the deepest common level. They concluded that there is a significant fraction of the variability (about $35 \%$ ) in the total transport arising from variations in the baroclinic field. In agreement, a large variability in baroclinic transport was found from upperocean XBT measurements (Sprintall 2003) and from numerical models (Olbers and Lettmann 2007). Firing et al. (2011) found from direct velocity observations that the depth-mean and shear components of the transport variability in the upper $1000 \mathrm{~m}$ are of similar size.

The difficulty in determining the reference for the ACC and the total transport remains an ongoing issue (Meredith et al. 2011; Firing et al. 2011). Cunningham et al. (2003) found that including lowered acoustic Doppler current profiles (LADCP) data to obtain the total transport along the SR1b sections increased the uncertainty of the transport estimate. Recently, Griesel et al. (2012) combined mean dynamic ocean topography products with climatological ocean density fields. Resulting ACC transports were generally higher than observational estimates. They attribute these discrepancies to a lack of mass conservation in the products as well as the difficulty in resolving the high temporal variability and small spatial scales characteristic of the Southern Ocean.

The Southern Ocean has been shown to be especially susceptible to climate change. In the past three decades a strengthening of the westerly winds in the Southern Ocean has been observed (Thompson and Solomon 
2002), thereby resulting in a higher southern annular mode (SAM) index. Aoki (2002) found significant correlations between observations of sea level variations around Antarctica and the SAM on time scales from a few days to several weeks, and Meredith et al. (2004) found significant interannual variability in the circumpolar westerly winds that was correlated to fluctuations in the observed ACC transport. Baroclinic ACC transport estimates have been remarkably steady despite a SAM increase. From the analysis of profiling floats and historical hydrography, Böning et al. (2008) suggested that ACC transport is relatively insensitive to decadal changes in wind stress. To date there is no observational evidence of a long-term increase in transport due to changes in the SAM.

Hydrographic transects are irregular and infrequent, making the analysis of variability or the detection of trends in the ACC transport very difficult. Sampling at high spatial and temporal resolution is necessary to avoid significant aliasing of high-frequency variability. Meredith and Hughes (2005) concluded that sampling with an interval shorter than a week was required to reliably monitor interannual changes in the ACC, and more rapid sampling is required to resolve subseasonal and seasonal variations.

The cDrake array was deployed in NovemberDecember 2007 in Drake Passage providing unprecedented temporal and spatial resolution to resolve the subseasonal-to-interannual variability and dynamics of the total ACC transport over a period of $4 \mathrm{yr}$ (Fig. 1; Chereskin et al. 2009, 2012). The array consists of 37 inverted echo sounders (IESs) equipped with bottom pressure gauges and current meters [current- and pressure-recording IESs (CPIES)] and 2 current-meter moorings on the northern continental slope and 1 on the southern continental slope. Among the specific goals of the cDrake array are to determine the time-varying total ACC transport, its vertical structure partitioned between baroclinic and barotropic components, and its lateral partitioning among the jets that compose the ACC.

The purpose of this study is to describe the mean, variability, and partitioning of the baroclinic component. The cDrake array provides an excellent opportunity to determine the unaliased mean full-depth baroclinic transport and also to explore the time scales of the observed fluctuations using the 4-yr dataset from December 2007 through October 2011. Here, we adopt the Cunningham et al. (2003) definition of baroclinic transport. This allows straightforward comparisons to previous ACC transport estimates using hydrography. This paper is structured as follows. In section 2, we introduce the data used in this study. Section 3 establishes the methodology to determine the baroclinic transport and discusses the associated error estimates. Section 4 details the mean and temporal variability of the observed baroclinic flow, the lateral partitioning of the baroclinic transport among fronts, and the vertical distribution of baroclinic transport among neutral density layers. Section 5 compares our baroclinic transport estimate with previous studies. Section 6 provides the discussion and summary.

\section{Data}

\section{a. cDrake experiment overview}

The cDrake array was deployed in NovemberDecember 2007 to monitor the ACC transport in Drake Passage and operated continuously until late 2011. The array consists of a transport line spanning $800 \mathrm{~km}$ across Drake Passage and a local dynamics array located where surface variability is at a maximum between the SAF and PF (Fig. 1a). The mean positions of the SAF, PF, and SACCF are nominally at $56^{\circ}, 58.5^{\circ}$, and $60.75^{\circ} \mathrm{S}$, respectively (Orsi et al. 1995). Four prominent bathymetric features across Drake Passage are the steep northern continental slope, the Shackleton Fracture Zone (SFZ) that slants across our array near $58.5^{\circ} \mathrm{S}$, the South Shetland Trench near $61.5^{\circ} \mathrm{S}$, and the southern continental slope (Figs. 1a,b).

Throughout this study, we describe and analyze data from the transport line (sites labeled in Fig. 1a). The nominal positions, water depths, and periods of the records of the CPIES located in the transport line and the current-meter moorings are given in Tables 1 and 2, respectively. The CPIES in the transport line span from the 500-m isobath in the north to the $1200-\mathrm{m}$ isobath in the south (Figs. 1a,b). Two deep current-meter moorings are located on the northern slope and one on the southern slope (Figs. 1a,b). The spatial resolution between CPIES sites ranges between 45 and $65 \mathrm{~km}$, with higher spatial resolution north of $57.5^{\circ} \mathrm{S}$ and within the SAF and near topography. The CPIES measures bottom pressure, round-trip acoustic travel time to the sea surface and back $\tau$, and currents $50 \mathrm{~m}$ above the bottom using an Aanderaa Doppler current sensor. On the northern slope each of the two moorings carries three current meters at 100,300, and $600 \mathrm{~m}$ above the bottom. On the southern slope, the mooring carries two current meters at 100 and $300 \mathrm{~m}$ above the bottom (Fig. 1b; Table 2). The three currentmeter moorings aim to directly observe for $2 \mathrm{yr}$ the vertical structure of the flow and to resolve bottom trapping along the northern and southern continental slopes. After deployment in 2007, yearly telemetry cruises were carried out in 2008, 2009, and 2010, and CPIES instruments were replaced as needed. Recovery of all the instruments took place in December 2011.

Overall, data return was very good with only a few data losses. C01 was located at the steep continental 
TABLE 1. Nominal position, water pressure, and dates of CPIES distributed across the transport line in Drake Passage from north to south.

\begin{tabular}{|c|c|c|c|c|}
\hline CPIES name & Lat (S) & Lon $(\mathrm{W})$ & Water pressure (dbar) & Dates \\
\hline $\mathrm{C} 01$ & $54^{\circ} 58.1^{\prime}$ & $64^{\circ} 35.5^{\prime}$ & 476 & 15 Nov 2007-21 Nov 2011 \\
\hline $\mathrm{C} 02$ & $55^{\circ} 14.2^{\prime}$ & $64^{\circ} 31.1^{\prime}$ & 1783 & $\begin{array}{l}15 \text { Nov } 2007-17 \text { Nov } 2008 \text { and } \\
17 \text { Dec } 2009-21 \text { Nov } 2011\end{array}$ \\
\hline $\mathrm{C} 03$ & $55^{\circ} 36.0^{\prime}$ & $64^{\circ} 24.2^{\prime}$ & 3662 & 15 Nov 2007-21 Nov 2011 \\
\hline $\mathrm{C} 04$ & $55^{\circ} 55.2^{\prime}$ & $64^{\circ} 18.2^{\prime}$ & 3866 & 15 Nov 2007-21 Nov 2011 \\
\hline $\mathrm{C} 21$ & $56^{\circ} 12.8^{\prime}$ & $64^{\circ} 12.0^{\prime}$ & 3890 & 12 Dec 2008-21 Nov 2011 \\
\hline $\mathrm{C} 05^{*}$ & $56^{\circ} 20.6^{\prime}$ & $64^{\circ} 10.1^{\prime}$ & 3829 & 15 Nov 2007-5 Dec 2008 \\
\hline $\mathrm{C} 19$ & $56^{\circ} 41.5^{\prime}$ & $63^{\circ} 54.7^{\prime}$ & 3445 & 15 Nov 2007-21 Nov 2011 \\
\hline $\mathrm{C} 06$ & $56^{\circ} 50.9^{\prime}$ & $63^{\circ} 49.3^{\prime}$ & 3928 & 15 Nov 2007-21 Nov 2011 \\
\hline $\mathrm{C} 07$ & $57^{\circ} 08.7^{\prime}$ & $63^{\circ} 38.1^{\prime}$ & 4136 & 15 Nov 2007-21 Nov 2011 \\
\hline $\mathrm{C} 08$ & $57^{\circ} 26.4^{\prime}$ & $63^{\circ} 28.0^{\prime}$ & 3684 & 15 Nov 2007-21 Nov 2011 \\
\hline $\mathrm{C} 18$ & $57^{\circ} 41.8^{\prime}$ & $63^{\circ} 18.3^{\prime}$ & 3608 & 15 Nov 2007-5 Dec 2008 \\
\hline $\mathrm{C} 09^{* *}$ & $57^{\circ} 57.0^{\prime}$ & $63^{\circ} 08.6^{\prime}$ & 4000 & 15 Nov 2007-21 Nov 2011 \\
\hline $\mathrm{C} 10$ & $58^{\circ} 30.1^{\prime}$ & $62^{\circ} 45.2^{\prime}$ & 2502 & 15 Nov 2007-21 Nov 2011 \\
\hline $\mathrm{C} 11$ & $58^{\circ} 59.0^{\prime}$ & $62^{\circ} 26.0^{\prime}$ & 3840 & 15 Nov 2007-21 Nov 2011 \\
\hline $\mathrm{C} 13$ & $60^{\circ} 05.5^{\prime}$ & $61^{\circ} 45.9^{\prime}$ & 3956 & 15 Nov 2007-21 Nov 2011 \\
\hline $\mathrm{C} 14$ & $60^{\circ} 36.2^{\prime}$ & $61^{\circ} 22.4^{\prime}$ & 3667 & 15 Nov 2007-21 Nov 2011 \\
\hline $\mathrm{C} 15$ & $61^{\circ} 06.7^{\prime}$ & $61^{\circ} 02.8^{\prime}$ & 3836 & 15 Nov $2007-17$ Oct 2011 \\
\hline $\mathrm{C} 16$ & $61^{\circ} 43.4^{\prime}$ & $60^{\circ} 32.9^{\prime}$ & 2508 & 15 Nov 2007-21 Nov 2011 \\
\hline $\mathrm{C} 17$ & $61^{\circ} 57.7^{\prime}$ & $60^{\circ} 22.5^{\prime}$ & 1267 & 15 Nov 2007-21 Nov 2011 \\
\hline
\end{tabular}

* Recovered in December 2008 due to current-meter failure.

** Noisy $\tau$ record during first deployment year.

slope north of the passage in shallow water. Strong currents dragged the instrument to different depths episodically throughout the deployment, introducing numerous changes in both the pressure and $\tau$ records that were difficult to identify and remove. Therefore, data from $\mathrm{C} 01$ have been excluded from the transport analysis. Close to the northern slope, $\mathrm{C} 02$ was recovered in November 2008 due to current-meter failure, and subsequently the site was reoccupied with a new CPIES. In austral spring 2009 it was not possible to establish communication with the CPIES leaving a data gap of $1 \mathrm{yr}$ at $\mathrm{C} 02$ (from 18 November 2008 to 16 December 2009; Table 1). C02 was redeployed and worked without problems until recovery in November 2011. As described in section $2 \mathrm{~d}$, this gap was filled by using the data from the northernmost current-meter mooring. $\mathrm{C} 05$ was recovered in austral spring 2008 due to current-meter failure, and abrupt increases in pressure were found in the records, indicating that the instrument slid down the steep topography. Therefore, for subsequent years the site was relocated to flatter topography and termed C21. The nearby records at $\mathrm{C} 05$ and $\mathrm{C} 21$ are merged together to obtain a 4-yr-long time series at the nominal C05 site. C09 measured noisy $\tau$ data during the first deployment year; thus, it was recovered in austral spring 2008 and replaced. The noisy $\tau$ record was replaced with data from the neighboring $\mathrm{C} 18$ site. All moored current meters worked well except the uppermost current meter at M02, which failed a few months after deployment (but has a complete temperature record) and the bottommost current meter and temperature sensor at M02, which failed immediately after deployment (Table 2).

\section{b. Data acquisition and processing}

A detailed description of the data processing can be found in Tracey et al. (2013). Here we will describe briefly how the measured $\tau$, pressure, and currents are processed. The IES measures the $\tau$ of a $12.0-\mathrm{kHz}$ pulse

TABLE 2. Position, nominal current-meter pressures, water pressure, and dates of current-meter moorings at the northern and southern slopes of the section.

\begin{tabular}{lllcrc}
\hline \hline Name & Lat $(S)$ & Lon $(\mathrm{W})$ & $\begin{array}{c}\text { Nominal current-meter } \\
\text { pressures (dbar) }\end{array}$ & $\begin{array}{c}\text { Water pressure } \\
(\text { dbar })\end{array}$ & Dates \\
\hline M01 & $55^{\circ} 01.6^{\prime}$ & $64^{\circ} 34.5^{\prime}$ & $920,1220,1420$ & 1520 & 16 Nov 2007-20 Nov 2009 \\
M02 & $55^{\circ} 21.9^{\prime}$ & $64^{\circ} 28.7^{\prime}$ & $2755, * 3055,3255^{* *}$ & 3355 & 16 Nov 2007-21 Nov 2009 \\
M03 & $61^{\circ} 47.4^{\prime}$ & $60^{\circ} 30.1^{\prime}$ & 1684,1884 & 1984 & 23 Nov 2007-30 Nov 2009 \\
\hline
\end{tabular}

\footnotetext{
* Current meter failed a few months after deployment.

** Current meter and temperature sensor failed immediately after deployment.
} 
from the sea bottom to the surface and back. Within every hour, the CPIES transmits 24 pings, and subsequently they are processed using a two-stage windowing and median filtering in order to reduce scatter due to sea surface roughness, yielding an hourly estimate. The bottom pressure values are averaged to obtain hourly estimates. Subsequently, the pressures are dedrifted and leveled to a common geopotential following Donohue et al. (2010), and tidal response analysis is performed to remove the semidiurnal and diurnal tides (Munk and Cartwright 1966). Two corrections are applied to the currents: rotation to true north accounting for local magnetic declination and a sound speed correction appropriate for each instrument's depth. The hourly time series of all variables are 72-h low-pass filtered using a fourth-order Butterworth filter, and $24 \mathrm{~h}$ at the beginning and end of the records are truncated to avoid transients. Last, all variables are subsampled to yield 12-hourly estimates. Throughout this paper the filtered 12-hourly estimates of $\tau$ will be used, except for the aliasing calculation (section 4c) where we use the hourly records of $\tau$ and construct a baroclinic transport time series to examine the high-frequency variance of geopotential height.

\section{c. Gravest empirical mode}

The gravest empirical mode (GEM) (Meinen and Watts 2000) is a lookup table created from hydrography in the region. The table relates $\tau$ integrated between the surface and a selected reference depth $\tau_{\text {index }}$ to hydrographic profiles of temperature $T$, salinity $S$, and specific volume anomaly $\delta$. In the ACC region, where pronounced meridional gradients and associated strong baroclinicity exist, the GEM technique has been successfully utilized (Sun and Watts 2001; Swart et al. 2010; Behnisch et al. 2013). South of Australia, the GEM fields captured more than $97 \%$ of the density and $T$ variance (Sun and Watts 2001). Furthermore, Watts et al. (2001) found very good agreement between estimates of $T$ and $S$ from IES measurements through the GEM relation with directly measured $T$ and velocity from currentmeter moorings south of Australia in the ACC. For full details on how a GEM is constructed, the reader is referred to Donohue et al. (2010).

For the cDrake experiment, the construction of the GEM is discussed in Cutting (2010) and Firing et al. (2014). Here, we briefly review important aspects and the appendix provides additional details. A reference depth of 2000 dbar is chosen, as a compromise between having a large number of casts to construct the GEM by including Argo profiles and requiring the $\tau_{\text {index }}$ to capture the gravest mode variability of the water column. The cDrake GEM is based on 526 hydrographic profiles coming from Argo floats, cDrake calibration CTDs, and historical hydrography in the region with the condition that all selected casts extended to 2000 dbar or greater (Cutting 2010). The latitudinal extent of the region was chosen between $54.5^{\circ}$ and $64.5^{\circ} \mathrm{S}$ and was determined by the landmasses, while the longitudinal extent of the region spans between $57^{\circ}$ and $80^{\circ} \mathrm{W}$ and was chosen based on the range of $\tau$ values corresponding to the casts on those regions. The profiles cover the time period 19722011. Recently, Meijers et al. (2011a,b) constructed a "satGEM." Satellite altimeter SSH was used as a proxy for geopotential height. Profiles of $T$ and $S$ were determined as a function of time and space using a timeinvariant GEM. Differences between satGEM and hydrography are then interpreted as either "adiabatic" (e.g., due to a shift of circumpolar fronts) or "diabatic" (e.g., due to changes in water masses). In the cDrake GEM, the bulk of the casts are from the last decade, and most of the deep-reaching casts were acquired during the cDrake cruises. Thus, our GEM is time invariant, and any secular or interannual water mass variability contributes to the scatter.

To remove errors associated primarily with upperocean seasonal variability, the seasonal signals are removed from the GEM and $\tau$ records following Watts et al. (2001) and Cutting (2010). The GEM is created by fitting a spline curve to these deseasoned data as a function of $\tau_{\text {index }}$ at a suite of pressure levels. To guide the appropriate amount of smoothing to perform, a priori errors (Bindoff and Wunsch 1992; Sun and Watts 2001) were estimated for each level from the hydrocasts and compared to the GEM rmse profiles. Subsequently the fitted curves were interpolated to a 10-dbar spacing spanning from the surface to $4500 \mathrm{dbar}$.

At the southernmost site (C17; Fig. 1), the GEM calculated using a 2000-dbar reference level does not account for the large $\tau$ values due to the cold temperatures in the Antarctic continental slope. Therefore, another GEM is constructed to be used at the $\mathrm{C} 17$ site with $\tau_{\text {index }}$ integrated between the surface and 1000 dbar. The same method as described above is employed by including additional CTD casts to 1000-1500 dbar close to the coast at the southern end of Drake Passage.

GEM quality is expressed as how much of the signal variance is captured by the GEM (e.g., Meinen and Watts 2000; Sun and Watts 2001). Both the $T$ and $\delta$ GEMs explain over $93 \%$ of the variance in the upper $2500 \mathrm{dbar}$ and for $S$ in the 500-1500-dbar range, below which the accuracy of the GEM remains high and the $S$ signal is relatively weak. The geopotential anomaly GEM explains $98 \%$ and $70 \%$ at the surface and 3800 dbar, respectively. These are illustrated in Fig. A4 in the appendix. Firing et al. (2014) compared cDrake CPIES-determined 


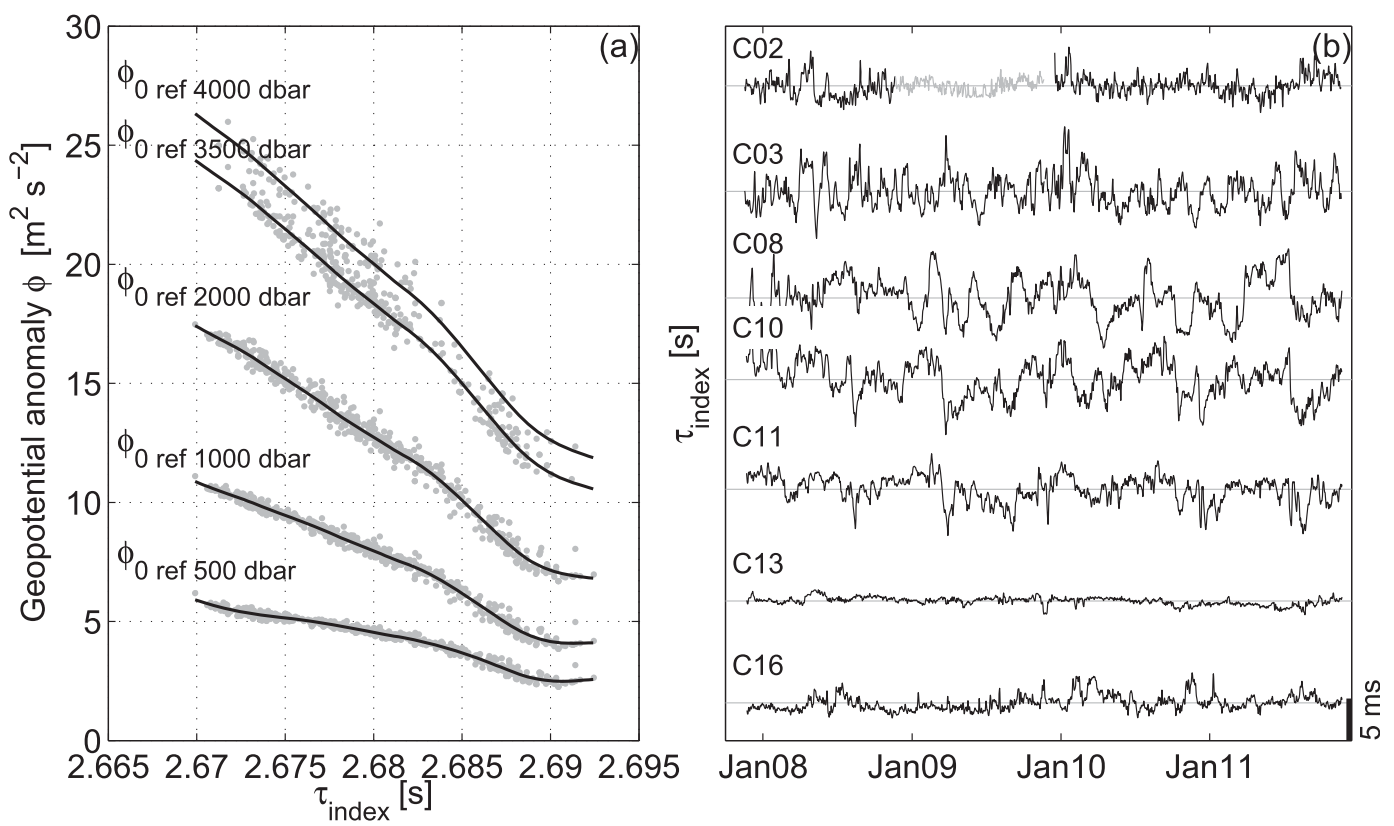

FIG. 2. (a) Geopotential anomaly $\phi$ at the surface relative to five pressure levels as a function of round-trip travel time between the surface and 2000 dbar (i.e., $\tau_{\text {index }}$ ) from the individual CTDs (gray dots) together with $\phi$ at the surface relative to these five pressure levels from the GEM lookup table (black lines). (b) Time series of $\tau_{\text {index }}$ at representative sites across Drake Passage. The gray line at $\mathrm{C} 02$ is the $\tau_{\text {index }}$ record estimated using M01 current-meter data (see section $2 \mathrm{~d}$ ).

temperatures to a nearby mooring (termed M4) deployed during the Drake experiment (Ferrari et al. 2012) in northern Drake Passage. Firing et al. (2014) found excellent agreement: rms differences (correlations; $r^{2}$ ) are $0.25^{\circ} \mathrm{C}(0.85)$ at $520 \mathrm{dbar}, 0.09^{\circ} \mathrm{C}(0.90)$ at $930 \mathrm{dbar}$, and $0.07^{\circ} \mathrm{C}(0.86)$ at $2540 \mathrm{dbar}$. At $520 \mathrm{dbar}$, where the rms difference is largest, M4 temperature has a standard deviation of $0.47^{\circ} \mathrm{C}$, indicating that the rms difference is about half the signal standard deviation. Additional analyses of these records (not shown) reveals that the coherence-squared estimates between the records are high $(>0.85)$ for frequencies lower than $1 / 10$ day $^{-1}$ and decrease to about 0.6 for higher frequencies, indicating that most of the GEM scatter arises from high-frequency variability.

Moreover, Fig. 2a shows a robust relationship between $\tau_{\text {index }}$ and the geopotential anomaly $\phi$ throughout the water column. The rms difference between $\phi$ from the individual CTDs versus $\phi$ from the GEM lookup table integrated between the surface and 500, 1000, 2000,3500 , and $4000 \mathrm{dbar}$ is $0.11,0.18,0.31,0.44$, and $0.52 \mathrm{~m}^{2} \mathrm{~s}^{-2} \mathrm{rms}$, respectively. As expected, the scatter increases when integrating over larger depths.

\section{d. Acoustic travel time $\tau$ measurements}

To interpret CPIES-measured $\tau$ utilizing the GEM table, $\tau$ values are converted to $\tau_{\text {index }}$ as described in
Tracey et al. (2013). Time series of $\tau_{\text {index }}$ at representative sites across the passage are shown in Fig. 2b. The large, lower-frequency $\tau$ fluctuations are observed at sites located under the meandering SAF and PF (such as $\mathrm{C} 03, \mathrm{C} 08, \mathrm{C} 10$, and C11). CPIES located on the continental slopes, such as $\mathrm{C} 02$ and $\mathrm{C} 16$, exhibit variability with higher frequency. The records at sites occupied in the southern portion of the Drake Passage poleward of the PF (like C13) exhibit considerably weaker variability. The gap during the second year at $\mathrm{C} 02$ is filled by using the M01 current-meter data (Table 2) to create a "pseudo-IES" travel time $\tau_{\mathrm{cm}}$. Following Meinen and Watts (2000), the temperature lookup table $T_{\mathrm{GEM}}(p, \tau)$ is inverted to obtain $\tau\left(p_{\mathrm{cm}}, T_{\mathrm{cm}}\right)$, where $T_{\mathrm{cm}}$ is the temperature measured by current meters at three levels. Pressure $p_{\mathrm{cm}}$ was measured only at the top level, so that record was offset by the mooring line lengths to provide estimates of $p_{\mathrm{cm}}$ at the two deeper levels. A single $\tau_{\mathrm{cm}}$ record is created by averaging the three estimates. The $\tau_{\mathrm{cm}}$ appears to underestimate the variability at $\mathrm{C} 02$ located farther offshore (gray line in Fig. 2b).

The error estimates closely follow the steps outlined in Baker-Yeboah et al. (2009) and Donohue et al. (2010). There are four independent sources of error for 72-h low-pass-filtered $\tau$ : (i) the scatter in $\tau$ due to sea surface roughness of $0.07 \mathrm{~ms}$; (ii) the conversion to a purely steric $\tau$ by removal of pressure-associated 
pathlength change has an error of $0.02 \mathrm{~ms}$ (mostly associated with uncertainty on the pressure drift); (iii) the error associated with the conversion from measured $\tau$ to a dynamic $\tau$ independent of a latitudinal dependence of gravity of $0.03 \mathrm{~ms}$; and (iv) the conversion of the dynamic $\tau$ (typically for 3500-4200-dbar depth) to $\tau_{\text {index }}$ (for 2000-dbar index pressure) of $0.15 \mathrm{~ms}$. Thus, the total error in $\tau_{\text {index }}$ results from summing the independent errors in a square root of the sum of squares sense and amounts to $0.17 \mathrm{~ms}$ [ $\delta \tau=$ $\left.\sqrt{(0.07)^{2}+(0.02)^{2}+(0.03)^{2}+(0.15)^{2}}=0.17 \mathrm{~ms}\right]$. To obtain the error for the unfiltered hourly record of $\tau$, we substitute for (i) the scatter of $0.45 \mathrm{~ms}$ associated with typical scatter of 24 pings in an hour of $1.7-2.5 \mathrm{~ms}$ (using a midrange value of $2.2 \mathrm{~ms}$ gives $2.2 / \sqrt{24}=0.45 \mathrm{~ms}$ ). Substituting this number in $\delta \tau$, we get an error of $0.48 \mathrm{~ms}$ for hourly $\tau$. The pseudo-IES $\tau_{\mathrm{cm}}$ has an estimated accuracy of $4.6 \mathrm{~ms}$ (bias of $4.5 \mathrm{~ms}$ from the current-meter pressure and temperature measurement errors and scatter of $0.9 \mathrm{~ms}$ from the inverted lookup table). This error estimate is improved by excluding the bias. Because M01 and C02 were not collocated, an offset in their mean $\tau$ is expected regardless of the bias error, so the bias is eliminated by forcing the means at M01 and $\mathrm{C} 02$ during the first year to agree. Thus, the accuracy of $\tau_{\mathrm{cm}}$ is $0.9 \mathrm{~ms}$. This is consistent with the standard deviation of the difference between $\mathrm{M} 01 \tau_{\mathrm{cm}}$ and $\mathrm{C} 02 \tau$ of $1.2 \mathrm{~ms}$ determined for the period when the records overlapped.

\section{Baroclinic transport calculation}

\section{a. Methods}

This section describes how the baroclinic transport time series through the passage is computed using the $\tau$ records at each site in the transport line (Figs. 1a,b; Table 1). There is a robust relationship between vertical profiles of $T, S, \delta$, and therefore of geopotential height anomaly $\phi(p)$ and the measured $\tau$, expressed in the GEM lookup table (Fig. 2a and the appendix). Using $\phi(p)$ between selected pressure levels $p$ and a reference pressure $p_{\text {ref }}\left[\phi(p)=\int_{p_{\text {ref }}}^{p} \delta\left(p^{\prime}\right) d p^{\prime}\right]$ at two laterally separated sites, geostrophy allows us to compute vertical profiles of the normal component of the baroclinic velocity $u_{g}(p)$ at a pressure $p$ relative to $p_{\text {ref }}$ between two sites 1 and 2:

$$
u_{g}(p)=\frac{\phi_{1}(p)-\phi_{2}(p)}{f L}
$$

where $f$ is the Coriolis parameter and $L=x_{1}-x_{2}$, where $x_{1}$ and $x_{2}$ represent the locations of the sites.
The geostrophic baroclinic transport at each time step is then computed as the vertical and lateral integral of the geostrophic velocities $u_{g}(p)$ from the surface to a reference depth level over horizontal separation between sites. To facilitate comparison with previous estimates from hydrography, the baroclinic transport is computed relative to the bottom.

To obtain the full across-passage baroclinic flow, we compute transports in three regions and subsequently we sum them: 1) the northern slope inshore of the 3500-m isobath between $\mathrm{C} 01$ and $\mathrm{C} 03,2$ ) the middle of the section between $\mathrm{C} 03$ and $\mathrm{C} 16$, and 3) the southern slope inshore of the 2500-m isobath between $\mathrm{C} 16$ and C17 (Fig. 1b). The reported variability of the 4-yr time series in each region represents one standard deviation from the mean.

The northern slope transport is estimated as follows. Between $\mathrm{C} 01$ and $\mathrm{C} 02$, we only estimate the mean velocity structure to capture the mean transport contribution because the C01 time series failed (section 2a). First, between the surface and $400 \mathrm{~m}$, we estimate the velocity shear relative to $400 \mathrm{~m}$ [deepest common level (DCL) between $\mathrm{C} 01$ and $\mathrm{C} 02$ ] from CTD data from each of the five cDrake cruises, and subsequently the five shear profiles are averaged together. Next, between 400 and $927 \mathrm{~m}$ (mean measured upper M01 current-meter depth), the mean velocity shear of $11 \mathrm{~cm} \mathrm{~s}^{-1}$ is determined by averaging 40 LADCP casts taken near $\mathrm{C} 02$ on the cDrake cruises. Then, the 400-927-m shear is added to the mean upper M01 current-meter velocity rotated in the direction of the northern transport line (Table 2) of $8 \mathrm{~cm} \mathrm{~s}^{-1}$, resulting in $19 \mathrm{~cm} \mathrm{~s}^{-1}$. A mean profile from the surface to $927 \mathrm{~m}$ is created by referencing the mean CTDderived shear profile by this amount. Next, the mean absolute velocity profile between $927 \mathrm{~m}$ and the bottom at $1427 \mathrm{~m}$ is determined by the deep mean velocities from the three current meters at the M01 mooring rotated in the direction of the northern transport line (Table 2). Subsequently, a mean absolute velocity profile from the surface to $1427-\mathrm{m}$ depth with 2-dbar spacing is created by linear interpolation. Finally, to be consistent with our barotropic convention, the mean absolute velocity profile is referenced to zero at $1427-\mathrm{m}$ depth. Integrating this mean velocity profile over a distance of $29 \mathrm{~km}$ between $\mathrm{C} 01$ and $\mathrm{C} 02$ and through $1427-\mathrm{m}$ depth gives $4.8 \mathrm{~Sv}$, with an error of $3.3 \mathrm{~Sv}$. The accuracy of the mean transport of $3.3 \mathrm{~Sv}$ is calculated as $\sqrt{\sigma_{\mathrm{CTD}}^{2}+\sigma_{\mathrm{LADCP}}^{2}+\sigma_{\mathrm{cm}}^{2}}$, where $\sigma_{\mathrm{CTD}}=0.9 \mathrm{~Sv}, \sigma_{\mathrm{LADCP}}=1.6 \mathrm{~Sv}$, and $\sigma_{\mathrm{cm}}=2.7 \mathrm{~Sv}$ are the transport standard deviations obtained for the CTDs, LADCPs, and current meters, respectively.

Then, we estimate the transport between $\mathrm{C} 02$ and $\mathrm{C} 03$ using Eq. (1). There is additional transport in the bottom triangle of the water column below the depth of the 
shallower of any neighboring pair of $\phi(p)$ profiles. To account for this transport and its error between $\mathrm{C} 02$ and $\mathrm{C} 03$, we use the following method. At each time step, we linearly interpolate $\tau$ on a 2-km lateral grid between $\mathrm{C} 02$ and $\mathrm{C} 03$. At each interpolated $\tau$, we look up $\phi(p)$ and evaluate the transport geostrophically for each subsection relative to and above $3500 \mathrm{~m}$ (approximate depth at $\mathrm{C} 03$ ) considering two referencing possibilities: (i) for each 2-km-wide subsection, we assume zero velocity below topography, which gives a transport of $15.1 \pm 11.6 \mathrm{~Sv}$; and (ii) for each 2-km-wide subsection, we assume zero velocity at the DCL above topography, which gives a transport of $13.4 \pm 10.4 \mathrm{~Sv}$. Finally, (iii) we estimate the baroclinic transport between $\mathrm{C} 02$ and $\mathrm{C} 03$ relative to $3500 \mathrm{~m}$, which gives a transport of $16.1 \pm$ 12.1 Sv. This close agreement indicates that our transport estimate relative to $3500 \mathrm{~m}$ is a good representation of the transport through the section between $\mathrm{C} 02$ and C03. The error due to possible additional transport in unresolved bottom triangles is given by the range of estimates of the mean baroclinic transport using the three different methodologies (i), (ii), and (iii) and amounts to $16.1-13.4=2.7 \mathrm{~Sv}$ between $\mathrm{C} 02$ and $\mathrm{C} 03$. The total transport along the northern slope, from $\mathrm{C} 01$ to $\mathrm{C} 03$, becomes $20.9 \pm 12.1 \mathrm{~Sv}$.

For the central deep passage (between $\mathrm{C} 03$ and $\mathrm{C} 16$ ), we compute the baroclinic velocity relative to the deepest level between each station pair across the passage using Eq. (1), and subsequently, we sum vertically and across the passage. The transport in this $716 \mathrm{~km}$ wide by approximately 4000-m-deep region is $105.4 \pm$ 14.7 Sv. To obtain bottom triangle error estimates across the topography at the SFZ (from C09 to C11), between C11 and C13, and close to the South Shetland Trench, the analyses are analogous to those described at the northern boundary. Applying the three methodologies produced a range in the mean baroclinic transport of $2.8 \mathrm{~Sv}$ between $\mathrm{C} 09$ and $\mathrm{C} 11,0.5 \mathrm{~Sv}$ between $\mathrm{C} 11$ and $\mathrm{C} 13$, and $0.6 \mathrm{~Sv}$ between $\mathrm{C} 15$ and $\mathrm{C} 16$. For the latter, the method mostly considers the sloping bathymetry near C16. Note in passing that there was a CPIES (termed C12) deployed between $\mathrm{C} 11$ and $\mathrm{C} 13$ during only the first $2 \mathrm{yr}$ of cDrake. Estimating the transport between $\mathrm{C} 11$ and $\mathrm{C} 13$ during those $2 \mathrm{yr}$ including $\mathrm{C} 12$ produced no change in the mean transport compared with the estimate excluding C12 (not shown).

On the southern slope, we evaluate the baroclinic transport relative to and above $1260 \mathrm{~m}$ between $\mathrm{C} 16$ and $\mathrm{C} 17$, which gives a mean transport of $1.4 \pm 1.7 \mathrm{~Sv}$. The mean velocities from the current meters at $\mathrm{M} 03$ rotated in the direction of the southern transport line (Table 2) are small: $0.9 \mathrm{~cm} \mathrm{~s}^{-1}$ at $\sim 1709 \mathrm{~m}$ and $-0.7 \mathrm{~cm} \mathrm{~s}^{-1}$ at $\sim 1909 \mathrm{~m}$. They indicate a zero crossing close to $\sim 1800 \mathrm{~m}$.
TABLE 3. Baroclinic transport error estimates (Sv) for the transport time series discussed in section 4 . The bottom triangle transport error (section 3a) for each transport time series is given in column 2. The total error for each transport time series combining the bottom triangle error and the uncertainty in the estimate of geopotential anomaly $\phi$ for 72-h and $>10$-day low-pass-filtered data are given in columns 3 and 4 , respectively. The total error calculation is detailed in section $3 \mathrm{~b}$.

\begin{tabular}{lccc}
\hline \hline & $\begin{array}{c}\text { Bottom } \\
\text { triangle }\end{array}$ & $\begin{array}{c}72 \text {-h low } \\
\text { pass }\end{array}$ & $\begin{array}{c}>10 \text {-day low } \\
\text { pass }\end{array}$ \\
\hline Northern slope & 2.7 & 6.9 & 3.7 \\
Central deep passage & 2.9 & 8.9 & 4.3 \\
Southern slope & - & 3.8 & 1.5 \\
\hline Total baroclinic & 4.0 & 11.9 & 5.9 \\
\hline SAF/PF & 3.9 & 9.3 & 5.1 \\
SACCF & 0.6 & 8.4 & 3.3 \\
\hline SASW/AAIW & - & 3.2 & 1.1 \\
UCDW & - & 5.8 & 2.0 \\
LCDW & 3.9 & 8.3 & 4.7 \\
AABW & 0.8 & 1.0 & 0.8 \\
\hline
\end{tabular}

Alternatively, if the velocity shears are extrapolated to zero velocity at $1800 \mathrm{~m}$, a mean transport of $1.5 \pm 1.8 \mathrm{~Sv}$ results. The small increase indicates that the deep shear does not significantly alter the transport at the southern slope. We choose to use the transport estimate referenced to zero at $1260 \mathrm{~m}$.

Layer transports based on neutral density $\left(\gamma^{n}\right.$; Jackett and McDougall 1997) surfaces as the limits are also calculated. The water masses in the ACC can be approximately separated by the following $\gamma^{n}$ layers (e.g., Speer et al. 2000; Naveira Garabato et al. 2003): Subantarctic Surface Water (SASW) and Antarctic Intermediate Water (AAIW) lighter than $27.5 \mathrm{~kg} \mathrm{~m}^{-3}$; Upper Circumpolar Deep Water (UCDW) $27.5-28.0 \mathrm{~kg} \mathrm{~m}^{-3}$; Lower Circumpolar Deep Water (LCDW) 28.0 $28.2 \mathrm{~kg} \mathrm{~m}^{-3}$; and Antarctic Bottom Water (AABW) denser than $28.2 \mathrm{~kg} \mathrm{~m}^{-3}$. For this analysis, layer depths are calculated at each time step by evaluating the $\gamma^{n}$ structure across the cDrake section looking up $T$ and $S$ from the GEM tables.

\section{b. Error analysis}

Transport uncertainty arises from two sources: the accuracy of the estimate of $\phi(p)$ and the error due to additional transport in the bottom triangle of the water column below the depth of the shallower of any neighboring pair of $\phi(p)$ profiles. Table 3 provides error estimates for the transports discussed in section 4 .

Here, we detail the methodology as applied to the central deep passage (between $\mathrm{C} 03$ and $\mathrm{C} 16$ ). The $\phi$ uncertainty has contributions from GEM and $\tau_{\text {index }}$ uncertainty and decreases with low-pass filtering separately as follows. As discussed in section 2c, part of the 
GEM scatter is due to high-frequency variability. Using the coherence estimates between M4-measured and CPIES-derived temperature as a guide, we classify errors for a 72-h low-pass-filtered $\phi$ and a $>10$-day lowpass-filtered $\phi$. The rms scatter about the fit between $\phi$ at the surface relative to $4000 \mathrm{~m}$ and $\tau_{\text {index }}$ is $\delta \phi=$ $0.52 \mathrm{~m}^{2} \mathrm{~s}^{-2}$; the standard error of the fitted curve is $\delta \phi=$ $0.17 \mathrm{~m}^{2} \mathrm{~s}^{-2}$ (Fig. 2a). For the 72-h low-pass-filtered data, the former is used; for the $>10$-day low-pass-filtered data, the latter is used.

The accuracy of the CPIES-measured $\tau_{\text {index }}$ is $\delta \tau=$ $0.17 \mathrm{~ms}$ (section $2 \mathrm{~d}$ ). Detailing the calculation for the $72-\mathrm{h}$ low-pass-filtered data, the combined $\phi$ error is $\Delta \phi=$ $\sqrt{[(\partial \phi / \partial \tau) \delta \tau]^{2}+(\delta \phi)^{2}}=0.53 \mathrm{~m}^{2} \mathrm{~s}^{-2}$. Assuming that the errors in the two $\phi$ estimates on either side of Drake Passage are independent, and substituting $\Delta \phi$ in $\Delta u_{g}=$ $(\sqrt{2} \Delta \phi) /(f L)$, along with $L=716 \mathrm{~km}$ and a Coriolis parameter $f$ of $1.2 \times 10^{-4} \mathrm{~s}^{-1}$, gives $0.87 \mathrm{~cm} \mathrm{~s}^{-1}$. The temporal average of the velocity shears between $\mathrm{C} 03$ and C16 indicates that the mean surface velocity is about 3 times the depth-averaged mean velocity profile (not shown). Assuming the velocity error decreases in a manner similar to the mean shear structure, the depth-averaged velocity error is $0.29 \mathrm{~cm} \mathrm{~s}^{-1}[(1 / 3) \times 0.87]$. The accuracy in the 72-h low-pass-filtered baroclinic transport from the accuracy of $\phi$ is $8.4 \mathrm{~Sv}$. The uncertainty associated with the sloping bathymetry near the SFZ, between $\mathrm{C} 11$ and $\mathrm{C} 13$, and between $\mathrm{C} 15$ and $\mathrm{C} 16$ is $2.8,0.5$, and $0.6 \mathrm{~Sv}$, respectively (section 3a). The bottom triangle error amounts to $\sqrt{(2.8)^{2}+(0.5)^{2}+(0.6)^{2}}=2.9 \mathrm{~Sv}$. The total error for the central deep passage transport is obtained by combining either the 72-h or $>10$-day low-pass-filtered values from the uncertainty in $\phi$ with the bottom triangle estimates. The total error for the central deep passage 72-h low-pass-filtered baroclinic transport becomes $\sqrt{(8.4)^{2}+(2.9)^{2}}=8.9$ Sv. Carrying out this calculation for the $>10$-day low-pass-filtered estimates results in an error of $4.3 \mathrm{~Sv}$. These calculations are repeated for the northern and southern slope regions. Errors for all three regions are listed in Table 3. The error for the baroclinic transport across the full Drake Passage is obtained by combining the errors from the three regions. We obtain error estimates for the total baroclinic transport of 11.9 and $5.9 \mathrm{~Sv}$, for $72-\mathrm{h}$ and $>10$-day low-pass-filtered records, respectively.

For the layer transports, there will be an additional source of baroclinic transport error arising from the uncertainty in determining layer thickness $h$. For each $\gamma^{n}$ surface we examine the difference between the $\gamma^{n}$ surface depth determined from CTDs and $\gamma^{n}$ surface depth determined from the GEM $T$ and $S$ using each CTD's $\tau_{\text {index }}$. This scatter provides an estimate of layer depth uncertainty $\Delta h$. The $\phi$ error is estimated from the scatter in the $\phi$ GEM relative to 4000 dbar integrated in



$55^{\circ} \mathrm{S} 56^{\circ} \mathrm{S} 57^{\circ} \mathrm{S} 58^{\circ} \mathrm{S} 59^{\circ} \mathrm{S} 60^{\circ} \mathrm{S} 61^{\circ} \mathrm{S}$

FIG. 3. The 1-yr temporal means of geopotential anomaly $\phi$ at the sea surface relative to $3500 \mathrm{~m}$ at each CPIES site. To confirm interannual consistency also at $\mathrm{C} 17$, the mean $\phi$ at the sea surface relative to $1260 \mathrm{~m}$ is shown. To facilitate comparison with $\mathrm{C} 17$, at $\mathrm{C} 16$ the mean $\phi$ at the sea surface relative to $1260 \mathrm{~m}$ is also shown. Colors indicate each deployment year: 2008 (black), 2009 (green), 2010 (red), and 2011 (blue). Error bars indicate standard error of the mean $\phi$. Labels at the top indicate the names of the CPIES sites. The gray shading indicates the mean positions of the SAF and the PF. Bathymetry section is also shown at the bottom. The position of the SFZ is indicated.

layers between 0 and 500, 500 and 1500, 1500 and 3500, and 3500 and $4000 \mathrm{dbar}$. For the 72-h low-pass-filtered data, the rms of the $h$ and $\phi$ scatter are used; for the $>10$-day low-pass-filtered data, the standard error is used instead. We assume that the $\phi$ error and the layer depth error are independent. The combined error becomes $L \sqrt{\left(\Delta u_{g} h_{\text {mean }}\right)^{2}+\left(u_{g_{\text {mean }}} \Delta h\right)^{2}}$, where $L, h_{\text {mean }}$, and $u_{g_{\text {mean }}}$ are the mean width, thickness, and velocity within the layer. There will be an additional contribution from the bottom triangles. These errors are provided in Table 3. The LCDW layer has the largest error due to the contribution of the bottom triangle transport error from the northern slope and the SFZ.

\section{Results}

\section{a. Mean baroclinic structure across Drake Passage}

The strikingly steady pattern of the annual-mean baroclinic structure across the passage is illustrated by the mean $\phi$ at the sea surface relative to $3500 \mathrm{~m}$ (except at $\mathrm{C} 17$, where we evaluate $\phi$ at the surface relative to $1260 \mathrm{~m}$ ) at each CPIES site (Fig. 3). To detect possible 


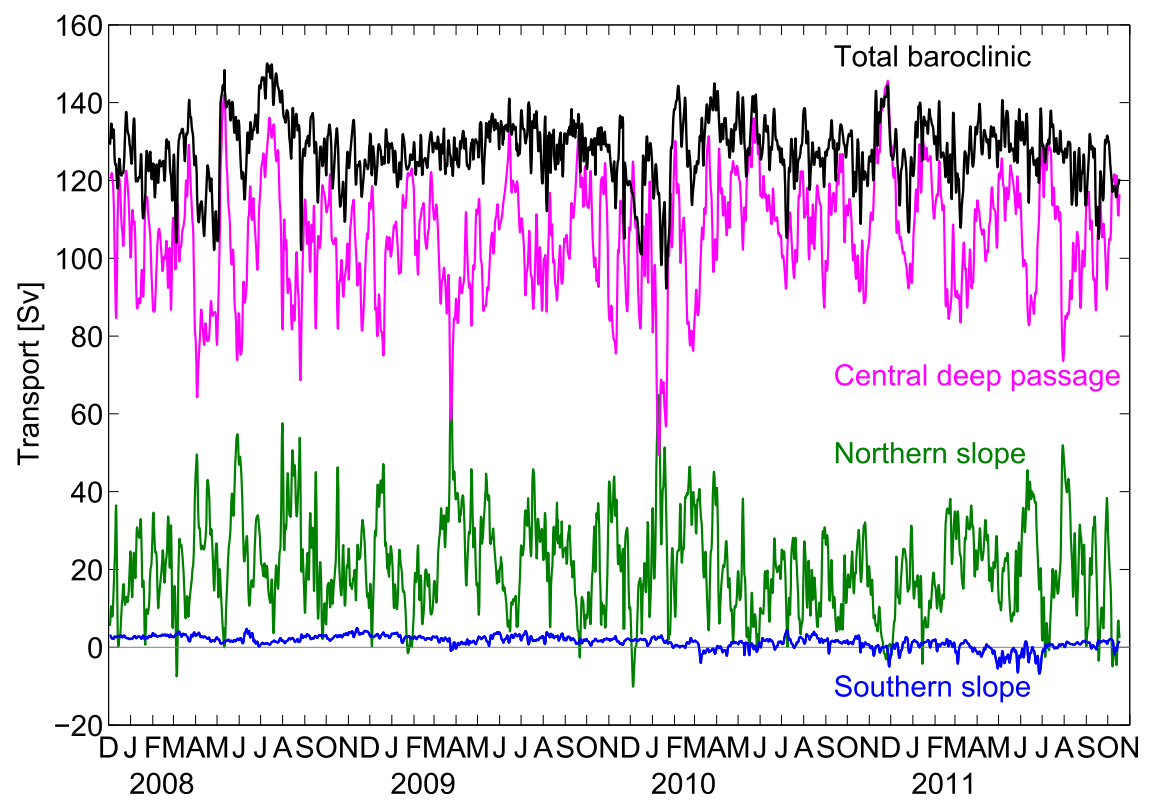

FIG. 4. Time series of the 72-h low-pass-filtered baroclinic transport through Drake Passage vertically integrated from the bottom to the surface (black) and its constituents: baroclinic transport at the northern slope north of the 3500-m isobath (green), in the central deep passage section excluding the slopes (magenta), and at the southern slope south of the 2500-m isobath (blue). Positive transports correspond to eastward flow. For details of the calculation see section $3 \mathrm{a}$.

interannual changes in the baroclinic structure, we evaluate the mean $\phi$ for four approximately year-long segments defined by cruises and data retrieval. Throughout this paper, the year-long segments are defined from December 2007 to mid-November 2008, from mid-November 2008 to mid-December 2009, from mid-December 2009 to mid-November 2010, and from mid-November 2010 to October 2011. The error bars represent the standard error of the mean (SEM) for each year-long segment as will be explained in section $4 \mathrm{~b}$.

The variability in baroclinic structure is presented in relationship to bathymetry (Fig. 3). For example, the SFZ is at $58.5^{\circ} \mathrm{S}$. Mean $\phi$ values decrease progressively southward, with the largest value of about $23 \mathrm{~m}^{2} \mathrm{~s}^{-2}$ at the northern slope of the section (C02 site). The SAF produces the gradient in mean $\phi$ north of $56.2^{\circ} \mathrm{S}(\mathrm{C} 05$ site). The PF produces the gradient in mean $\phi$ between $57.2^{\circ} \mathrm{S}$ (C08 site) and roughly $60^{\circ} \mathrm{S}$ (C13 site). Meanders in these fronts produce the increased SEM and some interannual variability.

It is possible to identify two plateaus of nearly constant $\phi$ values, indicating the transition between the different fronts that compose the ACC: one with nearly constant mean $\phi$ values of about $20 \mathrm{~m}^{2} \mathrm{~s}^{-2}$ between $56.2^{\circ}$ and $57.2^{\circ} \mathrm{S}$ and the other one approaching the southern boundary with nearly constant mean $\phi$ values of about $13 \mathrm{~m}^{2} \mathrm{~s}^{-2}$ between $60.4^{\circ}$ and about $61.1^{\circ} \mathrm{S}$.
The $\phi$ varies intra-annually (indicated by SEM bars) and interannually (indicated by the range of the four curves in Fig. 3). Comparing the four curves, we observe that the largest fluctuations (SEM) of the annualmean $\phi$ exceed $0.4 \mathrm{~m}^{2} \mathrm{~s}^{-2}$ between about 55.5 $\mathrm{S}(\mathrm{C} 04$ site) and $59.0^{\circ} \mathrm{S}$ (C11 site) and are associated with meanders of the SAF and PF and associated eddies. The fluctuations of the annual-mean $\phi$ are very small (less than $0.2 \mathrm{~m}^{2} \mathrm{~s}^{-2}$ ) south of $60^{\circ} \mathrm{S}$. The largest interannual changes (of about $0.3-1.2 \mathrm{~m}^{2} \mathrm{~s}^{-2}$ ) are found between the SFZ at $58.5^{\circ} \mathrm{S}$ and approximately $60^{\circ} \mathrm{S}$, also associated with interannual shifts of the PF.

\section{b. Time-variable ACC baroclinic transport}

Figure 4 shows the time series of the total baroclinic transport through Drake Passage and its components, the baroclinic transport at the northern slope, in the central passage section, and at the southern slope, calculated as outlined in section $3 \mathrm{a}$. The basic statistics of the transport time series shown in Fig. 4 are displayed in Table 4. Unless otherwise noted, the reported variability represents one standard deviation.

The full across-passage total baroclinic transport (black line) mean and standard deviation between 3 December 2007 and 17 October 2011 is $127.7 \pm 8.1 \mathrm{~Sv}$. The minimum value is $92.2 \mathrm{~Sv}$ on 20 January 2010, while the maximum value is $150.1 \mathrm{~Sv}$ on 10 July 2008 , yielding 
TABLE 4. Basic statistics of baroclinic transport (Sv) through the northern slope (green line in Fig. 4), the central deep passage excluding the slopes (magenta line in Fig. 4), the southern slope (blue line in Fig. 4), the full Drake Passage (total baroclinic; black line in Fig. 4), carried by SAF and PF (SAF/PF; upper line in Fig. 8), and carried by SACCF (SACCF; lower line in Fig. 8). The mean and std dev of annual and average baroclinic transports are given in columns 3-7. The min and max values are given in columns 8-9. The SEM is given in column 10 (see section $4 \mathrm{~b}$ for details of the calculation).

\begin{tabular}{|c|c|c|c|c|c|c|c|c|c|}
\hline & \multirow[b]{2}{*}{ Lat (S) } & \multicolumn{5}{|c|}{ Mean/std dev } & \multirow[b]{2}{*}{ Min } & \multirow[b]{2}{*}{ Max } & \multirow[b]{2}{*}{ SEM } \\
\hline & & 2008 & 2009 & 2010 & 2011 & Avg & & & \\
\hline Northern slope & $54^{\circ} 58.1^{\prime}-55^{\circ} 36.0^{\prime}$ & $22.5 / 11.8$ & $22.2 / 12.2$ & $19.7 / 11.8$ & $19.2 / 12.1$ & $20.9 / 12.1$ & -10.1 & 66.5 & 1.6 \\
\hline Central deep passage & $55^{\circ} 36.0^{\prime}-61^{\circ} 43.4^{\prime}$ & $103.2 / 15.1$ & $103.0 / 12.8$ & $107.2 / 15.8$ & 108.3/14.2 & $105.4 / 14.7$ & 49.4 & 145.6 & 1.9 \\
\hline Southern slope & $61^{\circ} 43.4^{\prime}-61^{\circ} 57.7^{\prime}$ & $2.4 / 0.8$ & $2.2 / 0.9$ & $1.0 / 1.3$ & $-0.1 / 1.7$ & $1.4 / 1.7$ & -6.7 & 4.9 & 0.2 \\
\hline Total baroclinic & $54^{\circ} 58.1^{\prime}-61^{\circ} 57.7^{\prime}$ & $128.1 / 9.9$ & $127.4 / 6.2$ & $127.9 / 8.7$ & $127.4 / 7.2$ & $127.7 / 8.1$ & 92.2 & 150.1 & 1.0 \\
\hline $\mathrm{SAF} / \mathrm{PF}$ & $54^{\circ} 58.1^{\prime}-60^{\circ} 05.5^{\prime}$ & $108.6 / 9.3$ & $106.3 / 8.0$ & $103.2 / 8.0$ & $100.6 / 8.3$ & $104.7 / 8.9$ & 65.1 & 131.1 & 1.1 \\
\hline SACCF & $60^{\circ} 05.5^{\prime}-61^{\circ} 57.7^{\prime}$ & $19.5 / 3.9$ & $21.1 / 5.0$ & $24.7 / 4.9$ & $26.8 / 5.9$ & $23.0 / 5.7$ & 11.2 & 49.4 & 0.7 \\
\hline
\end{tabular}

a transport range of about $58 \mathrm{~Sv}$ (almost half of its average). The annual-mean baroclinic transport and standard deviation (Table 4) for each deployment year of $128.1 \pm 9.9,127.4 \pm 6.2,127.9 \pm 8.7$, and $127.4 \pm$ $7.2 \mathrm{~Sv}$ (years 2008, 2009, 2010, and 2011, respectively) is remarkably steady, as previously shown by Fig. 3 .

The integral time scale is determined by the first zero crossing of the autocorrelation function of the total baroclinic transport time series. This yields an integral time scale of 12 days, indicating that every 24 days accumulates an independent estimate of the average. This results in about 60 effective degrees of freedom for the 4-yr record of baroclinic transport and an SEM of 1.0 Sv. To be conservative, we use 12 days as the integral time scale for all time series to compute the SEM (Table 4; column 10).

There is $20.9 \pm 12.1 \mathrm{~Sv}$ of eastward flow along the northern slope above $3500 \mathrm{~m}$ (green line), indicating that about $15 \%$ of the total baroclinic transport occurs there. While on average the transport along the northern slope contributes $20.9 \mathrm{~Sv}$, the transport range amounts to $77 \mathrm{~Sv}$, including several times when the transport exceeds $50 \mathrm{~Sv}$ and a few times when it is negative (as low as $-10 \mathrm{~Sv}$ ). The arbitrary choice of end point at $\mathrm{C} 03$ leads to the occasional negative transport as meanders and eddies pass by the region. The large variability at the northern slope arises according to how much of the SAF shifts north of $55.36^{\circ} \mathrm{S}$ (C03 site), plus additional small-scale baroclinic waves and processes.

The flow in the central passage amounts to $105.4 \mathrm{~Sv}$ with a large variability of $14.7 \mathrm{~Sv}$ (magenta line) and a transport range of $96 \mathrm{~Sv}$. Note the tendency for maxima and minima in the green and magenta curves to offset each other, resulting from the ACC fronts shifting between these two sections as they meander. The combined northern slope and central passage transport standard deviation is $8.6 \mathrm{~Sv}$, thus reducing the variability of the full across-passage baroclinic transport by almost $40 \%$ compared to the variability without including the northern slope (of approximately $14.7 \mathrm{~Sv}$ standard deviation).

The transport along the southern slope (blue line) is much smaller than at the northern slope and amounts to only $1.4 \mathrm{~Sv}$ and fluctuates by $\pm 1.7 \mathrm{~Sv}$. The transport range is about $12 \mathrm{~Sv}$, with the transport being mostly westward in the last year of the record. The latter is associated with eddies passing by the region.

Next, we examine the frequency distribution of the baroclinic transport. The total baroclinic transport time series displays markedly short-term variability. Transport fluctuations of about $35-55 \mathrm{~Sv}$ (from trough to peak) occur over periods as short as 2-3 weeks. For example, the transport increases by $41 \mathrm{~Sv}$ between 27 April and 11 May 2008, by 52 Sv between 20 January and 6 February 2010, and by $35 \mathrm{~Sv}$ between 20 October and 10 November 2010.

Spectra of the baroclinic transports are calculated using Welch's method with a 330-day Hamming window (Fig. 5). The spectrum of the total baroclinic transport has two significant peaks (at 95\% confidence) near 20 days and near 55 days, with a red spectrum beyond 90 days (Fig. 5a). About 34\% of the variance is associated with periods shorter than 30 days, and about $65 \%$ of the variance is associated with periods shorter than 60 days, indicating a large variability of the transport on monthly time scales and shorter.

The spectra of the baroclinic transport at the northern slope, in the central passage section, and at the southern slope are shown in Figs. 5b, 5e, and 5f, respectively. To further investigate the origin of the spectral peaks of each of these regions, the spectra of $\phi$ at the surface at the sites utilized as end points are also shown (Figs. 5c,d,g,h).

The frequency content of the total baroclinic transport (Fig. 5a) is mainly associated with the variability of $\phi$ at $\mathrm{C} 02$ (Fig. 5c). The total baroclinic transport and $\phi$ at C02 are well correlated $\left(r^{2}=0.84\right.$, significant at $5 \%$ error probability), indicating that surface $\phi$ at $\mathrm{C} 02$ reflects a large fraction of the depth-integrated baroclinic 


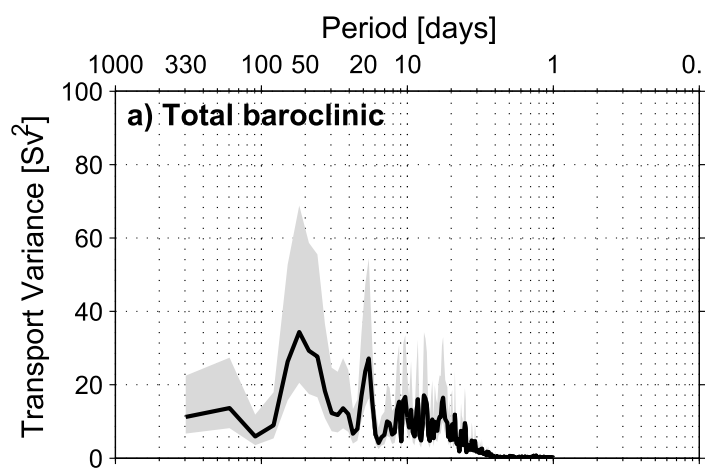

Period [days]
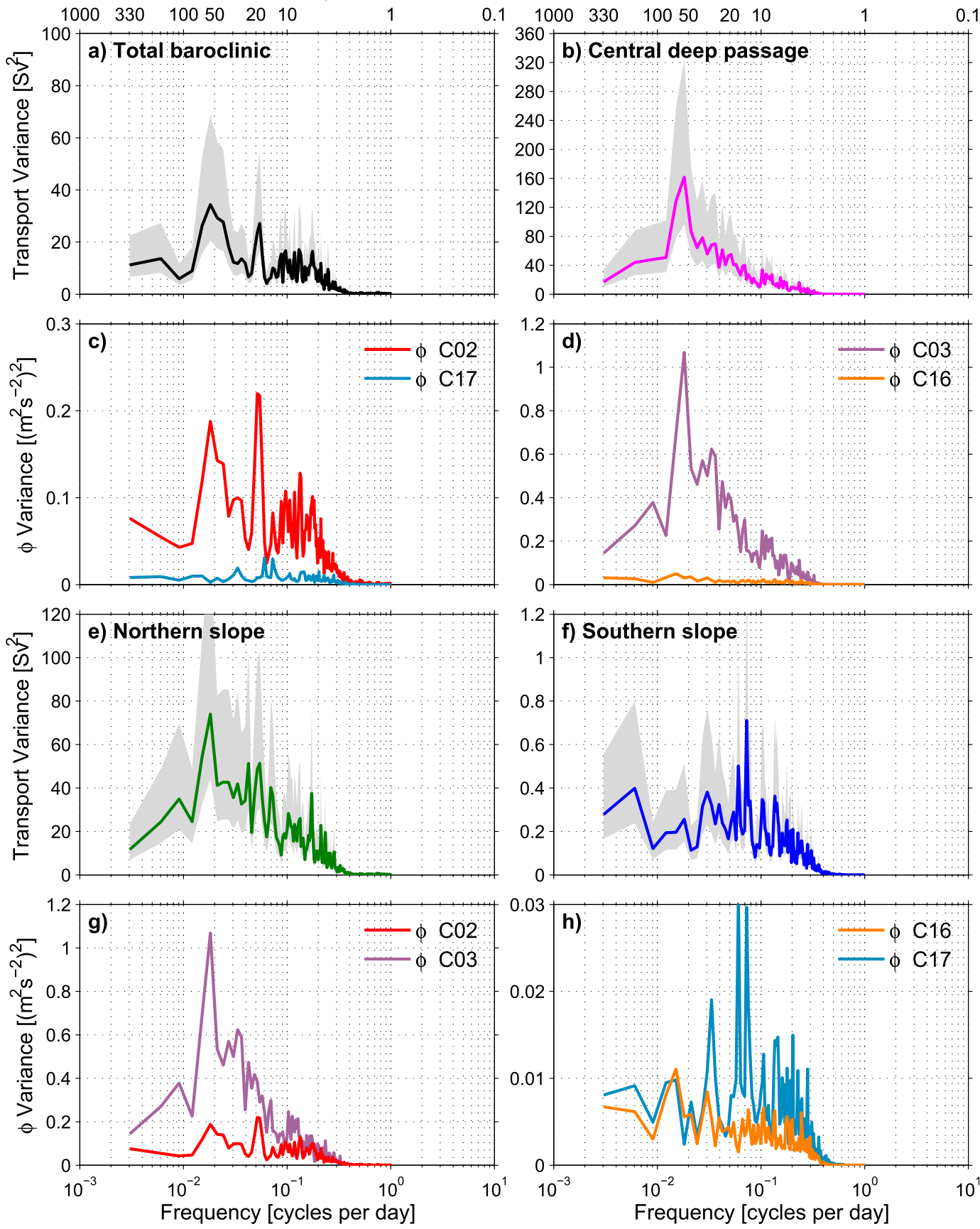

FIG. 5. Variance-preserving spectrum of (a) baroclinic transport time series and its constituents: (e) baroclinic transport at the northern slope, (b) in the central deep passage excluding the slopes, and (f) at the southern slope. Shaded confidence interval $(95 \%)$ is also shown. The variance-preserving spectrum of $\phi$ at the surface relative to $3500 \mathrm{~m}$ (except at the southern slope where $\phi$ at the surface relative to $1260 \mathrm{~m}$ is evaluated) at the sites utilized as end points to compute each transport time series is shown at (c) $\mathrm{C} 02$ and $\mathrm{C} 17$, (d) $\mathrm{C} 03$ and $\mathrm{C} 16,(\mathrm{~g}) \mathrm{C} 02$ and $\mathrm{C} 03$, and (h) C16 and C17. For clarity, confidence intervals for the spectra of $\phi$ are not shown. The spectra are computed as detailed in section $4 \mathrm{~b}$. Note the different scales on the $y$ axes. 
flow changes. The highest correlation between the two time series $\left(r^{2}=0.88\right)$ occurs for the 60-day high-passfiltered records. Thus, for periods shorter than 60 days, the variability of surface $\phi$ at $\mathrm{C} 02$ explains $77 \%$ of the variance of baroclinic transport.

At the northern slope about $67 \%$ of the variance is associated with periods shorter than 60 days (Fig. 5e), indicating large short-term variability. The frequency content is associated with the variability from both $\phi$ at $\mathrm{C} 02$ and $\phi$ at $\mathrm{C} 03$ (Fig. 5g). Note that $\phi$ at $\mathrm{C} 02$ and $\phi$ at $\mathrm{C} 03$ are moderately correlated $\left(r^{2}=0.37\right.$, significant at $5 \%$ error probability). The highest correlation between the two time series occurs for periods between 20 and 100 days $\left(r^{2}=0.45\right)$. The $\phi$ at $\mathrm{C} 02$ and $\phi$ at $\mathrm{C} 04$ (about $80 \mathrm{~km}$ south of $\mathrm{C} 02$ and $40 \mathrm{~km}$ south of $\mathrm{C} 03$ ) are not significantly correlated, indicating that correlation scales are small approaching the northern slope.

The largest baroclinic transport variance occurs in the central deep passage associated mainly with meandering of the SAF across site $\mathrm{C} 03$ at the northern end. The spectrum has a distinct peak around 55 days and a not so well-defined peak around 20-30 days (Fig. 5b), which are largely associated with the $\phi$ variability at $\mathrm{C} 03$ (Fig. $5 d$ ). The variance in this region is largely balanced by that at the northern slope as the current shifts between the two regions. Thus, the variance of the total transport (Fig. 5a) is smaller than for these two contributing subregions, yet all have peaks near 20 and 55 days.

Noting that northern slope and central deep passage transport standard deviations (12.1 and $14.7 \mathrm{~Sv}$, respectively) are larger than the total transport standard deviation $(8.1 \mathrm{~Sv})$, it seems natural to ask whether variability north of $\mathrm{C} 02$ might further reduce the total variability. We can estimate the standard deviation of transport sampled north of $\mathrm{C} 02$ by calculating the surface geostrophic velocity between $\mathrm{M} 01$ and $\mathrm{C} 02$ and convert that velocity standard deviation to a transport standard deviation by using the mean shear structure between $\mathrm{C} 01$ and $\mathrm{C} 02$ (section 3a). Recall that M01 is located $6 \mathrm{~km}$ south of $\mathrm{C} 01$. Our approach in estimating the full 4-yr baroclinic transport variability has been to use the best northernmost $\tau$ record available. The standard deviation of this baroclinic transport north of $\mathrm{C} 02$ is $1.3 \mathrm{~Sv}$. Three processes likely contribute to this small standard deviation: coastally trapped waves (CTW), SAF meanders north of $\mathrm{C} 02$, and noise from the M01 pseudo-IES $\tau_{\mathrm{cm}}$ estimates. CTW would presumably average to zero, while SAF meanders would rectify, each northward meander crest adding to the mean transport north of $\mathrm{C} 02$. While we do not know the partitioning of these processes, we can say that the sum is small, $1.3 \mathrm{~Sv}$ compared to $8.1 \mathrm{~Sv}$ of the total transport standard deviation, and only a fraction of the $1.3 \mathrm{~Sv}$ might oppose the 8.1-Sv variability south of $\mathrm{C} 02$.
At the southern end, the spectrum (Fig. 5f) is nearly two orders of magnitude smaller than observed at the northern slope. This indicates that the baroclinic shear is very weak at the southern end of Drake Passage. Unlike the other regions, higher-frequency fluctuations dominate the spectrum. Two distinct peaks occur near 14 and 33 days, and these are predominantly associated with the $\phi$ variability at $\mathrm{C} 17$ (Fig. 5h). The $50-80$-day broad peak that is so prominent in the other regions is much reduced here.

The total across-passage baroclinic transport is determined by the northern and southern end points. A comparison of the spectra in Figs. 5c and 5d clearly shows that the most energetic fluctuations occur across the whole spectrum at the northern end of the passage.

\section{c. Implications for satellite altimeter sampling at 10-day interval}

Satellite altimetry provides a useful tool to estimate the time-variable strength of upper-ocean velocities, as a basis for future monitoring of the ACC. Here we address one potential complicating factor: aliasing of highfrequency variability due to the insufficient temporal resolution of the 10-day repeat cycle of the Jason and Ocean Topography Experiment (TOPEX)/Poseidon altimeters, which has a Nyquist frequency of 1 cycle per 20 days. Temporal aliasing results when a continuous signal is subsampled at discrete times. Periodicities shorter than 20 days are aliased and appear as if they contributed to lower-frequency variability, thus complicating the interpretation of the satellite data. Altimeter products exist that map SSH to finer temporal resolution than observed, for example, Archiving, Validation, and Interpretation of Satellite Oceanographic data (AVISO) products are typically mapped at 7-day intervals and even daily maps have been produced. Yet it is important to note that mapping to higher temporal resolution (even when data from multiple satellites are included) does not change the intrinsic sampling resolution of the measurement system. Considerable effort is taken to account for high-frequency dynamic oceanic variability that is poorly sampled by the altimeter measurements. For example, AVISO uses a barotropic model to determine the response of a barotropic ocean to high-frequency wind and atmospheric forcing. Gille and Hughes (2001) examined aliasing of the barotropic component from bottom pressure records in Drake Passage. They found for periods between 20 and 40 days that aliased bottom pressure variance exceeds that of the resolved signals. We are unaware of any corrections for high-frequency baroclinic signals, despite a variety of high-frequency baroclinic processes along the northern slope, such as internal tides, topographic and shelf wave 
processes, and short-period eddies that contribute variability at periods shorter than 20 days (at the northern slope, $27 \%$ of the variance in baroclinic transport is associated with periods shorter than 20 days; Fig. 5e).

Using the hourly records of $\tau$ and the corresponding baroclinic transport time series, recognizing that lowpass filtering would be required to interpret the geostrophic variability, we can simulate 10 -day sampling and test how much energy is aliased into low frequencies. Following the methodology of Gille and Hughes (2001), we subsample the hourly record of the baroclinic transport at 10-day intervals and compute the spectrum. We iterate the calculation for the subsampled time series, offsetting the time series by one time step, until the spectra have been computed for every data point in the 10-day interval. Here, we use only the transport record calculated with the $\mathrm{C} 02 \tau$ record (excluding the pseudoIES values). Spectra are computed using the Welch method with a 330-day Hamming window. We split the record into a year-long segment plus a 2-yr-long segment and apply this procedure for each segment of the record, followed by ensemble averaging all the subsampled spectra (solid black line in Fig. 6a). Spectra from the subsampled data (open squares) have more energy for frequencies lower than the Nyquist frequency of 1 cycle per 20 days compared to the spectrum of hourly data (solid black line). In particular for baroclinic transport calculations, the fraction of spectral energy associated with periods shorter than 20 days is about $28 \%$. This implies that about $28 \%$ of apparent energy in the subsampled spectral estimates at periods longer that 20 days results from aliasing.

The fraction of aliased energy as a function of frequency is shown in Fig. $6 \mathrm{~b}$ [defined as 1 minus the ratio of the energy in the spectrum computed from the hourly record of baroclinic transport to the energy in the spectra computed from the subsampled record following Gille and Hughes (2001)]. For periods longer than 40 days, less than $40 \%$ of the energy has been aliased. For periods between 40 and 20 days, the fraction of aliased energy increases substantially to between $40 \%$ and $80 \%$. In consequence, the spectra computed from 10-day repeat measurements of the baroclinic contribution to SSH will only be representative of long-period variability (periods long compared to 40 days).

\section{d. ACC baroclinic transport distributed among fronts}

The distribution of the baroclinic transport between each CPIES pair versus time and latitude in Fig. 7 shows the time-varying position of the ACC fronts. We observe on any given day that the high transport tends to be concentrated in three regions: near $56^{\circ} \mathrm{S}, 58.5^{\circ} \mathrm{S}$, and south of $60^{\circ} \mathrm{S}$. In addition, surface $\phi$ contours that

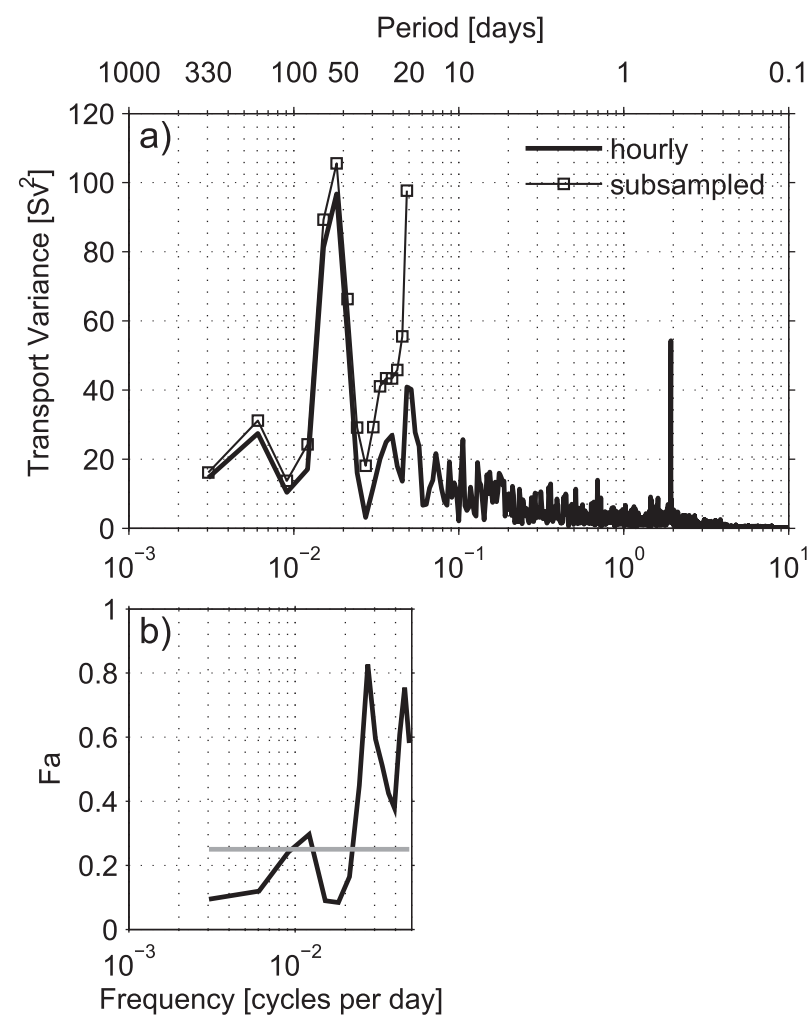

FIG. 6. (a) Variance-preserving spectrum of hourly record of baroclinic transport (black line) and of hourly record of baroclinic transport subsampled at the 10-day repeat cycle of the Jason altimeter computed as detailed in section $4 c$ (open squares). (b) Fraction of aliased energy $\mathrm{Fa}$ in spectrum computed from baroclinic transport subsampled into 10-day intervals. The gray horizontal line represents the limit of one-quarter of the energy being aliased.

coincide with the maximum mean $\phi$ gradient (Fig. 3) in the frontal regions found at the SAF, PF, and SACCF (bold lines) are overlain on baroclinic transport. Regions of strong transport often merge together, are not consistently associated with a single $\phi$ contour, and are strongly influenced by topography.

While the mean SAF is found along the northern slope, it frequently meanders southward. Large SAF meanders can extend to $58^{\circ} \mathrm{S}$, for example, February and April-May 2008 (Fig. 7a), from mid-April to mid-May 2009 (Fig. 7b), and April-May 2010 (Fig. 7c). During these periods, the SAF and PF are merged into a single front. Regions of strong negative transport along the mean SAF contour that occur north of $58^{\circ} \mathrm{S}$ indicate intervals when the SAF folds back on itself in an "S"-shaped meander, for example, July 2009, April 2010, and February 2011 (Figs. 7b,c,d).

The strongest eastward transports tend to occur when the PF is near the SFZ at $58.5^{\circ} \mathrm{S}(\mathrm{C} 10)$, but there are times when the PF migrates farther south near $60^{\circ} \mathrm{S}$ 


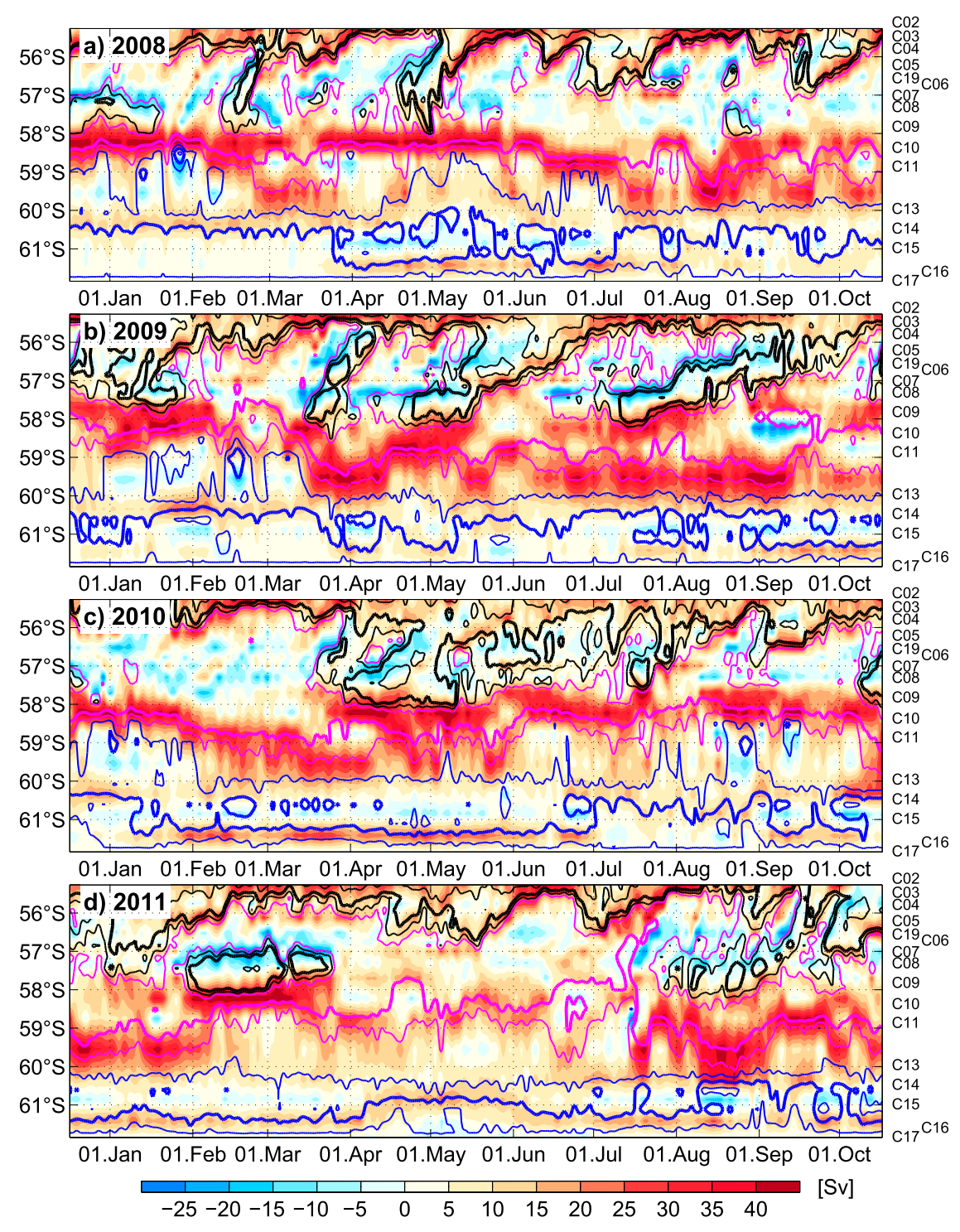

FIG. 7. Hovmöller diagram of 72-h low-pass-filtered baroclinic transport (Sv) in Drake Passage as a function of time and lat for each deployment year: (a) 2008, (b) 2009, (c) 2010, and (d) 2011. To facilitate interannual comparison, the same dates for the beginning and end for each deployment year are chosen. The thick overlaid contours indicate the values of the surface $\phi$ streamlines $\left(\mathrm{m}^{2} \mathrm{~s}^{-2}\right)$ associated with the max mean $\phi$ gradient for each frontal region from Fig. 3: SAF (black), PF (magenta), and SACCF (blue). The thin overlaid contours represent the max and min values of $\phi$ for each frontal region from Fig. 3. Labels on the right indicate names of the CPIES sites.

(C13). For instance, in the first half of 2008, the position of the PF is persistently located mostly between $58^{\circ}$ and $59^{\circ} \mathrm{S}$ (C09 and $\mathrm{C} 10$; Fig. 7a), while between June and October 2009 (Fig. 7b), October-November 2010 (Fig. 7c), and August 2011 (Fig. 7d), the PF is located farther south between roughly $59^{\circ}$ and $60^{\circ} \mathrm{S}$ (C11 and $\left.\mathrm{C} 13\right)$. From our measurements, the PF is not readily identified by a single $\phi$ contour; instead, the $\phi$ contour that identifies the PF appears to depend on whether the PF is north or south of the SFZ (C10).
Near the southern end of Drake Passage, a local maximum baroclinic transport occurs, mostly south of $60^{\circ} \mathrm{S}$ associated with the SACCF. The SACCF has a bimodal distribution occurring either near $60.3^{\circ} \mathrm{S}$ between $\mathrm{C} 13$ and $\mathrm{C} 14$ or, more frequently, near $61.4^{\circ} \mathrm{S}$ between $\mathrm{C} 15$ and $\mathrm{C} 16$. Similar to the PF, the $\phi$ that identifies the strongest gradient depends upon latitude. For example, in mid-January and early February 2009, when the transport maxima are near $60.3^{\circ} \mathrm{S}$, it is collocated with the mean SACCF $\phi$, while from mid-July through 


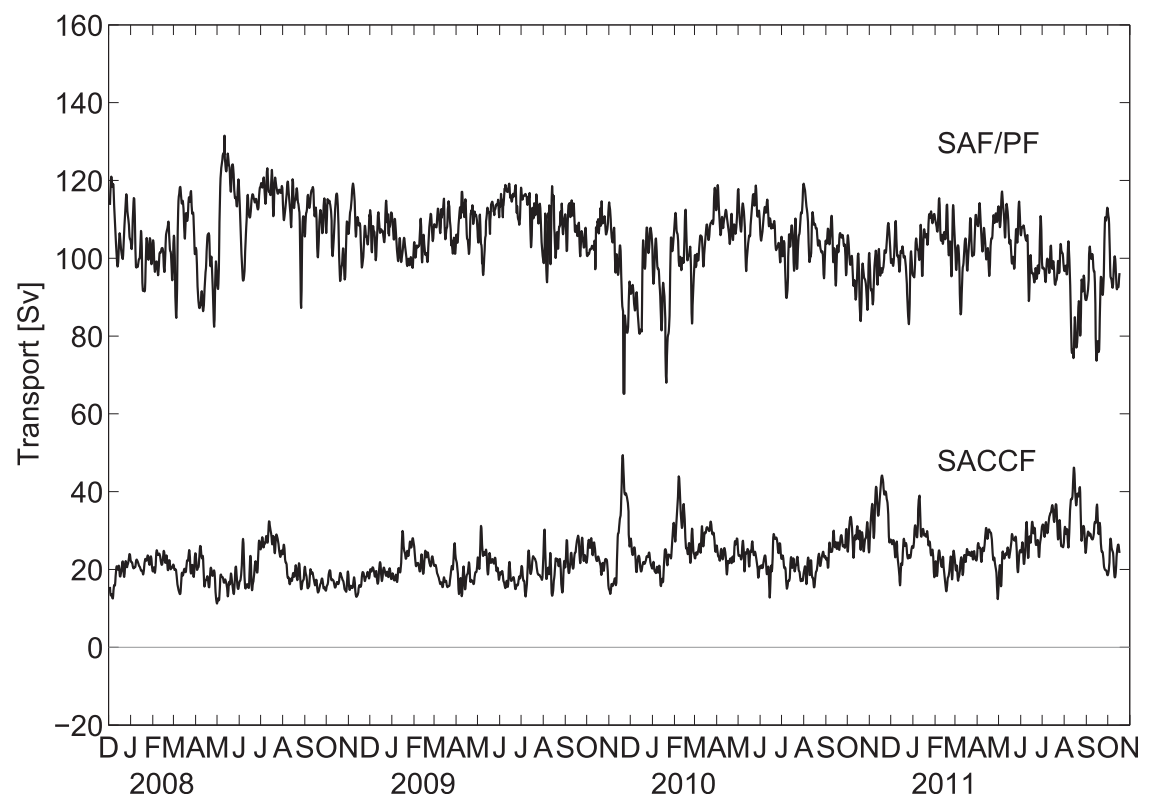

FIG. 8. Partition of 72-h low-pass-filtered baroclinic transport carried by the combined SAF and $\mathrm{PF}$ and that carried by the SACCF.

November 2009, when the transport maxima are near $61.4^{\circ} \mathrm{S}$, it is collocated with a lower $\phi$.

We report the time-varying baroclinic transport carried by the combined SAF and PF because they are not readily separable: SAF meanders reach as far south as $58^{\circ} \mathrm{S}$, and at times the SAF and PF merge together. Note that using a specific $\phi$ contour to demark the boundaries of a front would simply lead to a constant transport. We compute the transport between the northernmost end of the section (C01) and nearly $60^{\circ} \mathrm{S}$ (C13). The SAF and PF together carry $104.7 \pm 8.9 \mathrm{~Sv}$ (standard deviation) with a range of $66 \mathrm{~Sv}$ (SAF/PF; upper line in Fig. 8; Table 4), accounting for about $80 \%$ of the mean total baroclinic transport through Drake Passage. South of $60^{\circ} \mathrm{S}$, the SACCF carries $23.0 \pm 5.7 \mathrm{~Sv}$ with a range of $38 \mathrm{~Sv}$ (lower line in Fig. 8; Table 4). The $\mathrm{SAF} / \mathrm{PF}$ and SACCF time series exhibit partially compensating changes. Figure $7 \mathrm{~d}$ shows that the $\mathrm{PF}$ and SACCF are in close proximity in both the early and later parts of 2011 and farther apart in midyear. Times when the SACCF transport exceeds $40 \mathrm{~Sv}$ indicate sporadic migrations of the PF farther south up to the end point used for the calculation near $60^{\circ} \mathrm{S}$ (C13) (e.g., August 2011; Fig. 7d).

\section{e. ACC baroclinic transport in neutral density layers}

Here, we investigate the baroclinic transport of individual water masses through Drake Passage. Figure 9 shows a section of $\gamma^{n}$ computed following Jackett and McDougall (1997) from the CPIES distributed across
Drake Passage on a selected date. The $\gamma^{n}$ section is characterized by density surfaces that slope upward toward the south. As defined in section 3a, we consider four water masses: SASW/AAIW $\left(\gamma^{n}<27.5 \mathrm{~kg} \mathrm{~m}^{-3}\right)$, UCDW $\left(27.5<\gamma^{n}<28.0 \mathrm{~kg} \mathrm{~m}^{-3}\right)$, LCDW $(28.0<$ $\left.\gamma^{n}<28.2 \mathrm{~kg} \mathrm{~m}^{-3}\right)$, and AABW $\left(\gamma^{n}>28.2 \mathrm{~kg} \mathrm{~m}^{-3}\right)$.

The time series of the geostrophic transports for baroclinic velocities relative to the bottom classified according to $\gamma^{n}$ layers are shown in Fig. 10 (bottom). Their basic statistics are displayed in Table 5. The largest transports are found in the density classes of UCDW $(57.5 \pm 3.1 \mathrm{~Sv})$, followed by SASW and AAIW $(39.2 \pm 4.0 \mathrm{~Sv})$, LCDW $(27.7 \pm 2.1 \mathrm{~Sv})$, and AABW $(3.3 \pm 1.1 \mathrm{~Sv})$. The variability in AABW is quite large compared to its mean value, and the time series in Fig. 10 shows that pulses of higher transport occur episodically. The layer transport variability decreases with depth, with the largest variability found in waters lighter than $\gamma^{n}=$ $27.5 \mathrm{~kg} \mathrm{~m}^{-3}$. The upper three water masses are vertically coherent. Visual inspection reveals that the periods of relatively high or low total baroclinic transport [Fig. 10 (top)] are mostly associated with changes affecting the density classes of SASW/AAIW, UCDW, and LCDW, increasing upward with the baroclinic velocity profile. This is not surprising given that the density class of AABW is mainly present south of the SFZ with occasional intrusions north of the SFZ.

The steady, annual-mean, baroclinic transport in layers implies no interannual change in the flow associated with any particular water mass (Table 5). 


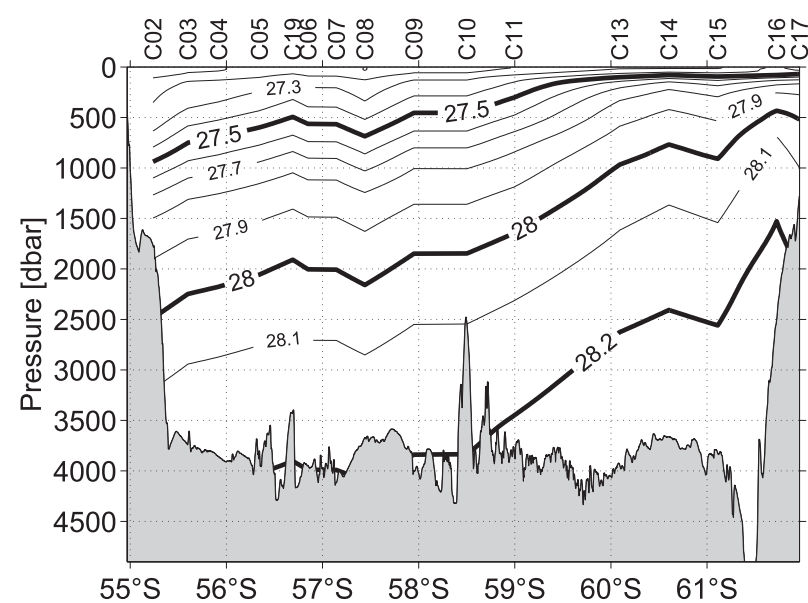

FIG. 9. Section of neutral density $\left(\gamma^{n} ; \mathrm{kg} \mathrm{m}^{-3}\right)$ from CPIES distributed across Drake Passage on 16 Mar 2010. Thick contours represent water mass limits: SASW and AAIW lighter than 27.5; UCDW 27.5-28.0; LCDW 28.0-28.2; and AABW denser than 28.2. Contour intervals are $0.1 \mathrm{~kg} \mathrm{~m}^{-3}$. Labels at the top indicate names of the CPIES sites.

\section{Comparison with previous ACC baroclinic transport estimates}

How do our estimates compare with previous transport estimates from hydrography? Published estimates of baroclinic transport through Drake Passage have used different depths and methods. The reported ISOS transports (Whitworth 1983; Whitworth and Peterson 1985) cannot be unambiguously separated into our baroclinic framework; therefore, no comparisons with the ISOS values are made. Instead, we compare our analyses to those that used comparable methods (Table 6).

Cunningham et al. (2003) combined seven hydrographic sections at the western end of the passage between 1975 and 1980 with six WOCE SR1b sections between 1993 and 2000. The combined sections gave $107.3 \pm 10.4 \mathrm{~Sv}$ baroclinic transport relative to and above $3000 \mathrm{~m}$ between 1975 and 2000. Using only the six SR1b sections, their transport relative to $3000 \mathrm{~m}$ was $112.7 \pm 5.2 \mathrm{~Sv}$ with a range of $105-118 \mathrm{~Sv}$. Our mean transport estimate recalculated using the same reference level is $100.4 \pm 6.0 \mathrm{~Sv}$ with a range of $75-117 \mathrm{~Sv}$, about $12 \mathrm{~Sv}$ smaller than their mean estimate between 1993 and 2000. The full-depth mean baroclinic transport estimate from just the six SR1b sections was even higher at $136.7 \pm 7.8 \mathrm{~Sv}$ with a range of $123.1-143.8 \mathrm{~Sv}$ between 1993 and 2000 (Cunningham et al. 2003).

However, additional SR1b sections taken between 2007 and 2011 yield full-depth mean transport of $127.9 \pm$ 8.0 Sv, which agree well in Fig. 10 with the cDrake time series mean of $127.7 \pm 8.1 \mathrm{~Sv}$ (Tables 4 and 6). It is plausible that the short-period variability observed in
cDrake might not be correlated with variations at SR1b, with the difference arising from coastal baroclinic features of alongstream scale shorter than the separation between cDrake and SR1b. Moreover sampling methodology and the 5-8-day time interval required to complete the SR1b CTD transect could account for differences of at least $2 \mathrm{~Sv}$. Hence, we conclude that the mean values from cDrake and SR1b, which differ by only $0.2 \mathrm{~Sv}$, agree well within the SEM for the five SR1b transects $(8.1 / \sqrt{5-1}=4 \mathrm{~Sv})$.

The comparison of the baroclinic transport in $\gamma^{n}$ layers from cDrake and SR1b between 2007 and 2011 is shown in Table 5. Both the means and the variability of the layer transports from the two transects are consistent with each other within each of the four layers considered here.

Other hydrographic sections have estimated baroclinic transports in Drake Passage in 2003-06. Koshlyakov et al. (2007) occupied sections in 2003 and 2005 along a line crossing the SFZ close to the cDrake array. Their baroclinic transport relative to the bottom was 122 and 130 Sv. In 2006, Renault et al. (2011) occupied two sections east of cDrake and west of SR1b. They evaluated baroclinic transport relative to the bottom, finding 150.5 and $136.3 \mathrm{~Sv}$. All these individual measurements fall within the range observed in our time series.

\section{Discussion and summary}

The 4-yr-long full-depth ACC baroclinic transport time series has a mean strength of $127.7 \pm 1.0 \mathrm{~Sv}$ (standard error) and a temporal standard deviation of $8.1 \mathrm{~Sv}$, with a large transport range of about $58 \mathrm{~Sv}$. Transport variations of about $40 \mathrm{~Sv}$ or more occur in periods as short as $2-3$ weeks. The annual-mean transport is remarkably steady during the $4 \mathrm{yr}$ of measurements.

The cDrake array was highly resolved both spatially and temporally. A careful error analysis has shown that the errors for all the transport time series presented here are small (section 3b; Table 3). In particular for the fullpassage ACC baroclinic transport, we obtain error estimates of 11.9 and $5.9 \mathrm{~Sv}$ for 72 -h and $>10$-day lowpass-filtered records, respectively. Our results show that the combination of the CPIES $\tau$ measurements with the GEM tables provides an excellent method for estimating the ACC baroclinic transport and its variability through Drake Passage.

We have shown that a large part of the variance $(65 \%)$ in our estimate of ACC baroclinic transport is associated with periods shorter than 60 days, demonstrating the short-term variability in the record. The spectrum has two peaks near 20 and 55 days. The dynamical drivers of these spectral peaks are currently being investigated. 




FIG. 10. (bottom) Time series of 72-h low-pass-filtered baroclinic transport through Drake Passage integrated in neutral density layers $\left(\gamma^{n} ; \mathrm{kg} \mathrm{m}^{-3}\right)$ : SASW and AAIW lighter than 27.5; UCDW 27.5-28.0; LCDW 28.0-28.2; and AABW denser than 28.2. (top) The sum of the four layers (total baroclinic) is added for comparison (identical to the total transport shown in Fig. 4, note the change of the transport scale on the $y$ axis). Overlaid on top are the five samples at the WOCE SR1b line (red dots).

Our analysis indicates that the baroclinic transport variability is dominated by density stratification variations at the northern slope of the section. Nearboundary processes close to the northern slope such as coastal, topographic and Kelvin-propagating waves, small-scale eddy variability, or locally forced motions such as wind-driven Ekman pumping may play a significant role in determining the observed fluctuations of the baroclinic transport.

Our results show that energetic high-frequency variability in the hourly spectrum of baroclinic transport, when subsampled at the 10-day repeat cycle of the Jason altimeter, is aliased to lower frequencies, particularly for periods between 20 and 40 days. These results complement the findings of Gille and Hughes (2001), who examined the barotropic (deep bottom pressure) component. It is likely that a correction to the steric signal in the altimeter measurements would be necessary to eliminate aliased high-frequency energy in the attempt to use altimetry for future ACC monitoring efforts.

The transport carried by the SAF and PF together amounts to $80 \%$ of the total baroclinic transport. From our observations, in general, three distinct regions associated with maxima in baroclinic transport are observed at any given time in Drake Passage. Sokolov and Rintoul (2009a) identified multiple frontal branches and concluded that if a front occurs it tends to occur at a specific SSH contour (or geopotential height $\phi$ contour). This is consistent with our analysis. We find that the $\phi$ most closely associated with the three fronts can change from day to day, but specific $\phi$ values tend to be favored (PF and SACCF, in particular). The SAF is a bit more complex because an " $\mathrm{S}$ "-shaped meander is often 
TABLE 5. Mean and std dev of baroclinic transport (Sv) relative to the bottom in neutral density layers. Column 1 indicates the water masses and column 2 indicates their neutral density range $\left(\gamma^{n} ; \mathrm{kg} \mathrm{m}^{-3}\right)$ : SASW and AAIW lighter than 27.5; UCDW 27.5-28.0; LCDW 28.0-28.2; and AABW denser than 28.2. Columns 3-7 indicate the mean and std dev of annual and average layer transports from cDrake. The average transports in $\gamma^{n}$ layers relative to the bottom from five hydrographic sections (between 2007 and 2011) at the WOCE SR1b line are displayed in column 8 . The sum of layer transports is shown in the final row (agreeing with Table 4). Regarding the listed std dev error bars, because the number of degrees of freedom of the cDrake estimates is about $15 \mathrm{yr}^{-1}$, the SEM estimates would be reduced by a factor of 4 compared to the values listed.

\begin{tabular}{|c|c|c|c|c|c|c|c|}
\hline \multirow[b]{2}{*}{ Water mass } & \multirow[b]{2}{*}{$\gamma^{n}\left(\mathrm{~kg} \mathrm{~m}^{-3}\right)$} & \multicolumn{5}{|c|}{ cDrake mean/std dev } & \multirow[b]{2}{*}{ SR1b mean/std dev } \\
\hline & & 2008 & 2009 & 2010 & 2011 & Avg & \\
\hline SASW/AAIW & $<27.5$ & $40.0 / 4.6$ & $39.5 / 3.6$ & $38.5 / 3.7$ & $38.7 / 3.9$ & $39.2 / 4.0$ & $36.8 / 4.6$ \\
\hline UCDW & $27.5-28.0$ & $57.9 / 3.9$ & $57.7 / 3.7$ & $57.3 / 2.4$ & $57.1 / 2.9$ & $57.5 / 3.1$ & $59.1 / 3.1$ \\
\hline LCDW & $28.0-28.2$ & $27.3 / 2.1$ & $27.2 / 1.7$ & $28.3 / 2.3$ & $28.0 / 1.9$ & $27.7 / 2.1$ & $27.8 / 1.7$ \\
\hline \multirow[t]{2}{*}{ AABW } & $>28.2$ & $2.9 / 0.8$ & $3.0 / 0.7$ & $3.8 / 1.4$ & $3.6 / 1.0$ & $3.3 / 1.1$ & $4.2 / 1.1$ \\
\hline & & $128.1 / 9.9$ & $127.4 / 6.2$ & $127.9 / 8.7$ & $127.4 / 7.2$ & $127.7 / 8.1$ & $127.9 / 8.0$ \\
\hline
\end{tabular}

present in northern Drake Passage, and the SAF and PF merge and separate within this region. Thus, our measurements show that at this particular location in Drake Passage, it is not possible to uniquely separate the SAF from the $\mathrm{PF}$ at all time steps; there is neither a single latitude separating the two fronts nor are there $\phi$ streamlines systematically associated with the local maxima in baroclinic transport.

We evaluated transports in four neutral density layers. The largest transports are found in the density class of UCDW, while the smallest transports are found in the density class of AABW. Layer transports are statistically steady.

The baroclinic transport estimates obtained from the occasional hydrographic sections at the downstream SR1b line can be compared with the 4-yr continuous cDrake estimates. From sections prior to 2000, Cunningham et al. (2003) estimated mean baroclinic transports about 9 Sv higher than cDrake. Preliminary evidence from that suite of sections (not shown here) is that mean SR1b transports within the four layers (SASW/AAIW, UCDW, $\mathrm{LCDW}$, and $\mathrm{AABW}$ ) are consistently higher than cDrake. This offers a promising topic for future investigation. The 9-Sv change in the total exceeds twice the standard error of the mean estimates. It indicates that the observed decrease in baroclinic transport between the decades $1993-2000$ and $2007-11$ is statistically significant at the $96 \%$ confidence level. For our present purposes, recall from Table 6 , however, the contemporaneous SR1b estimates between 2007 and 2011 agree well with the

TABLE 6. Baroclinic transport through Drake Passage (Sv) relative to and above the reference level indicated in column 3. Column 1 indicates the reference from which the information in columns 2-5 was taken. Values in column 4 indicate the mean and std dev. The cDrake estimates are given in the final two rows.

\begin{tabular}{|c|c|c|c|c|}
\hline Author & Dates & $\begin{array}{l}\text { Reference } \\
\text { level }(\mathrm{m})\end{array}$ & $\begin{array}{l}\text { Baroclinic transport } \\
\text { mean/std dev }\end{array}$ & Notes \\
\hline \multirow[t]{3}{*}{$\begin{array}{l}\text { Cunningham } \\
\text { et al. (2003) }\end{array}$} & $1975-2000$ & 3000 & 107.3/10.4 & $\begin{array}{l}\text { Hydrography western end passage } \\
\text { ( } 7 \text { sections) and SR1b (6 sections) }\end{array}$ \\
\hline & $1993-2000$ & 3000 & $112.7 / 5.2$ & SR1b (6 sections) \\
\hline & & bottom & $136.7 / 7.8$ & SR1b (6 sections) \\
\hline \multirow{2}{*}{$\begin{array}{l}\text { Koshlyakov } \\
\text { et al. (2007) }\end{array}$} & 2003 & bottom & 122 & 1 section \\
\hline & 2005 & bottom & 130 & 1 section \\
\hline \multirow{4}{*}{$\begin{array}{l}\text { Renault } \\
\quad \text { et al. (2011) }\end{array}$} & 2006 & 3000 & 117.0 & DRAKE (1 section) \\
\hline & & bottom & 150.5 & DRAKE (1 section) \\
\hline & 2006 & 3000 & 103.0 & DRAKE (1 section) \\
\hline & & bottom & 136.3 & DRAKE (1 section) \\
\hline \multirow[t]{3}{*}{ This study } & $2007-11$ & bottom & $127.9 / 8.0$ & SR1b (5 sections) \\
\hline & $\begin{array}{l}\text { November } \\
\text { 2007-October } \\
2011\end{array}$ & 3000 & $100.4 / 6.0$ & $\begin{array}{l}\text { cDrake CPIES (72-h low-pass } \\
\text { filtered) }\end{array}$ \\
\hline & & bottom & $127.7 / 8.1$ & $\begin{array}{l}\text { cDrake CPIES (72-h low-pass } \\
\text { filtered) }\end{array}$ \\
\hline
\end{tabular}


cDrake estimates, both in the mean and the variability. These results are suggestive of long-term variability in the baroclinic transport through Drake Passage that points to the need for sustained monitoring.

Our results reinforce the idea that full-depth ACC baroclinic transport variability is significant. Cunningham et al. (2003) reexamined the ISOS results and estimated that the ratio between total transport variability and baroclinic transport variability relative to and above $2500 \mathrm{~m}$ was $9.9 / 5.5 \mathrm{~Sv}$. During the 4-yr cDrake experiment, we find that baroclinic transport variability using the same reference level is $4.8 \mathrm{~Sv}$ (not shown), which compares well with that reported for the ISOS results. Full-depth ACC transport variability from cDrake (8.1 Sv) is nearly twice as large as that above $2500 \mathrm{~m}$. Efforts are underway to use the deep pressure and current-meter measurements from cDrake to provide the reference velocity to obtain the total ACC transport.

Ongoing work seeks to identify and understand the dominant physical driving mechanisms of the baroclinic transport fluctuations described here.

Satellite altimeter measurements are likely to be part of future ACC monitoring efforts in Drake Passage. Cunningham and Pavic (2007) successfully combined surface velocity anomalies from satellite SSH with measured surface currents from seven SR1b sections to obtain the total surface geostrophic velocities across the ACC between 1992 and 2004. From our measurements, a simple estimate of the meridional surface geopotential $\phi$ gradient just using $\phi$ time series at the northern $(\mathrm{C} 02)$ and the southern (C17) end points of the passage explains about $65 \%$ of the total baroclinic transport variance (not shown), indicating that the boundary-toboundary gradient in surface $\phi$ is representative of a large fraction of the depth-integrated baroclinic transport changes. In situ measurements of $\phi$ at the surface can be taken as a proxy for the steric signal in the altimeter measurements. If good agreement was found between our CPIES-derived surface $\phi$ and satellite SSH at the northern and southern end points in Drake Passage, SSH could be used to infer a large fraction of the variability of the baroclinic transport for periods longer than 20 days. Care should be taken with the interpretation of potentially aliased high-frequency signals to lower frequencies in the altimeter measurements (section 4d). Different satellite products will be evaluated and techniques for using satellite SSH to infer ACC baroclinic transport will be tested.

Acknowledgments. The National Science Foundation Office of Polar Programs supported this work under NSF Grants ANT-0636493 (SIO cDrake) and ANT0635437/ANT-1141802 (URI cDrake). We are very
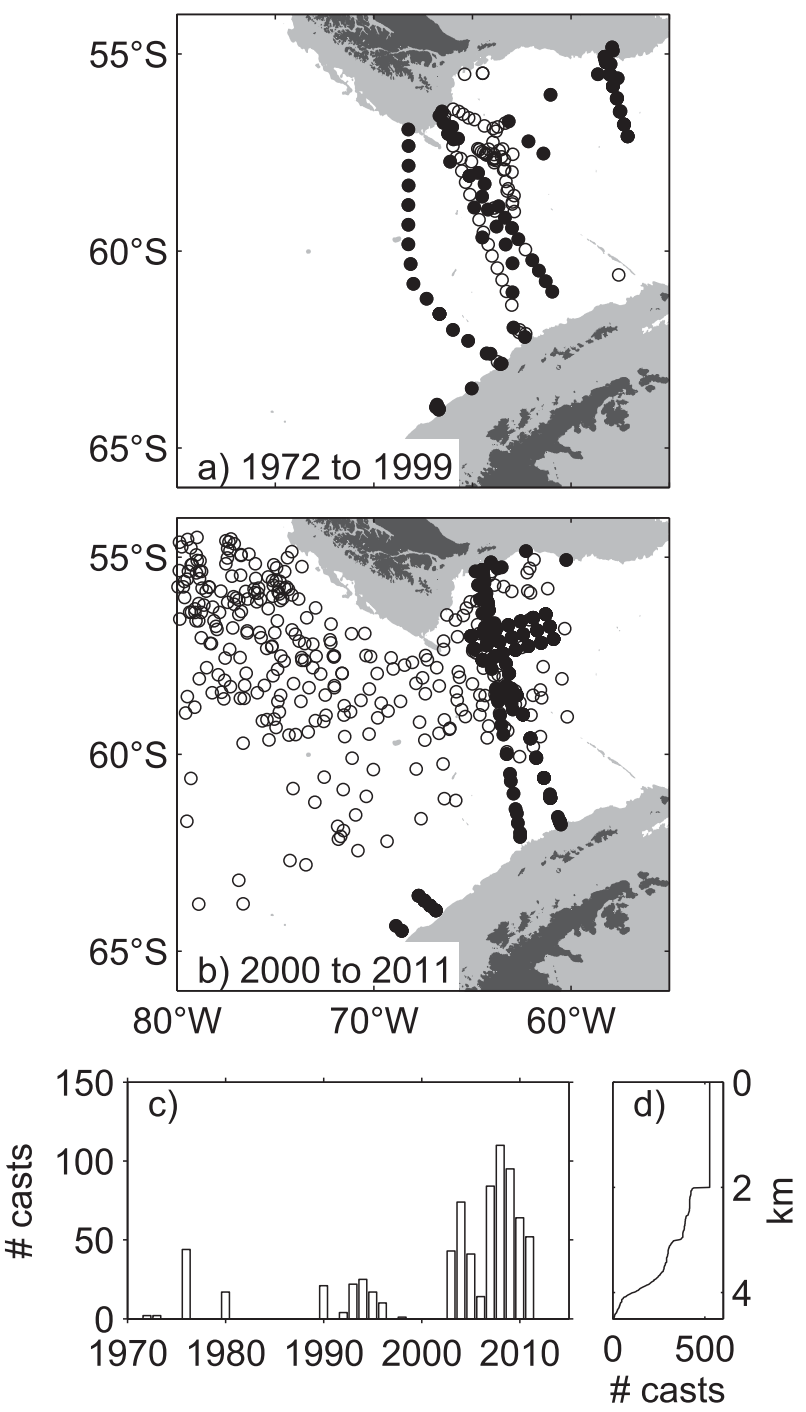

FIG. A1. Spatial and temporal distribution of the CTD and Argo profiles used to construct the cDrake GEM lookup tables. (a) Circles indicate the location of profiles taken between 1972 and 1999. Solid circles indicate casts that reached within $200 \mathrm{dbar}$ of the seafloor. Water depths shallower than $2000 \mathrm{~m}$ are shaded gray. (b) As in (a), but for profiles taken between 2000 and 2011. (c) Distribution of casts by year. (d) Distribution of $T$ and $S$ measurements by depth.

grateful to Teri Chereskin for coleading the cDrake project and for many helpful discussions. We thank the two anonymous reviewers for their thoughtful comments and suggestions, which improved this manuscript. We gratefully acknowledge the captains and crew of the RVIB Nathaniel B. Palmer and the staff of Raytheon Polar Services for their support during the seagoing activities. We thank Erran Sousa, Gerard Chaplin, and Dan Holloway for their valuable help in the CPIES instrumentation development and preparation. 
$\mathrm{T}\left[{ }^{\circ} \mathrm{C}\right]$
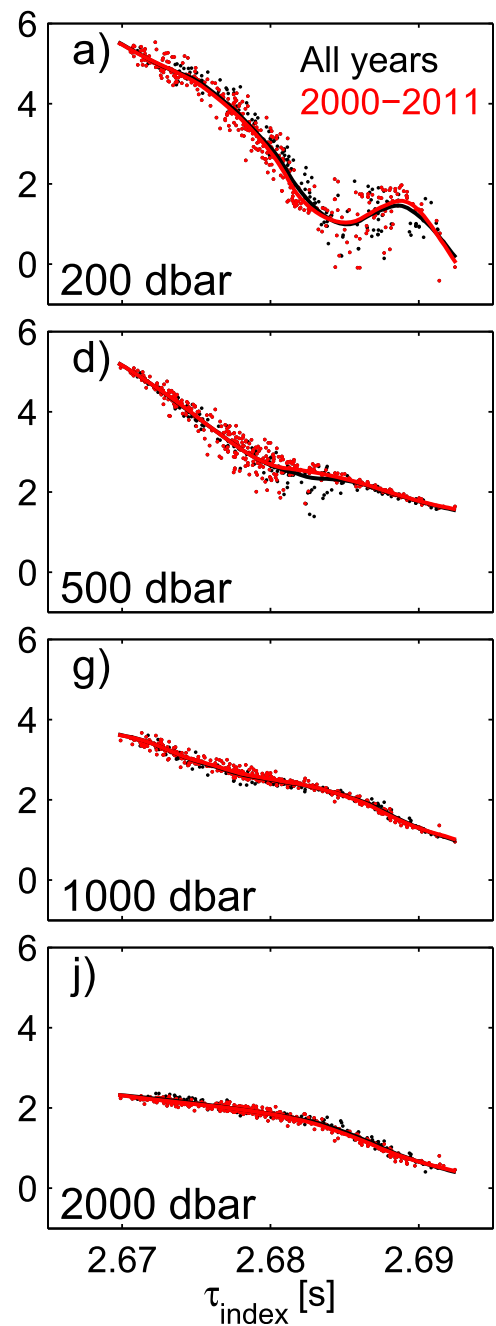

S [psu]
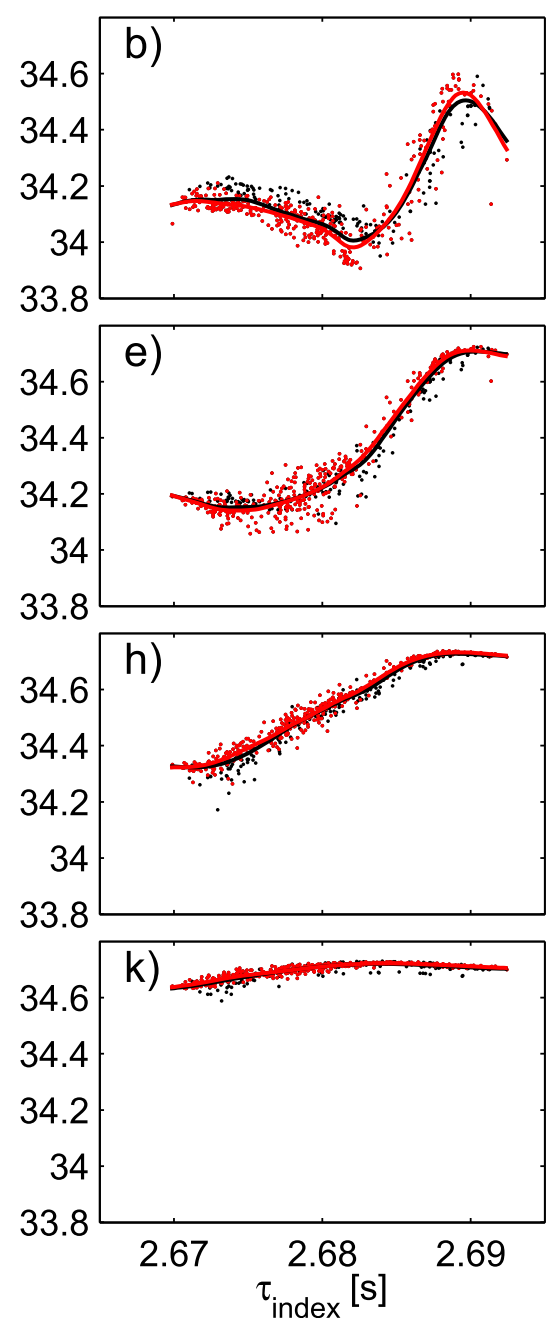


FIG. A2. Comparison of hydrographic casts (dots) and the fitted spline curves for two cases: all data from 1972-2011 (black) and just the data from 2000-11 (red). Temperature, salinity, and specific volume anomaly are shown for four levels.

The U.K. Natural Environment Research Council funded the SR1b section occupations used in this work through several core strategic research programs at the National Oceanography Centre Southampton and the British Antarctic Survey.

\section{APPENDIX \\ cDrake GEM}

The cDrake GEM lookup tables were discussed in section 2c. Here additional details about spatial and temporal distribution of the hydrographic casts used to construct the GEMs are presented and the robustness of the GEMs is demonstrated.
The spatial and temporal distributions of the CTD and Argo float profiles reaching to $2000 \mathrm{dbar}$ or greater are shown in Fig. A1. The histogram in Fig. A1c illustrates that the majority of the casts were taken after 2000 , primarily due to the availability of Argo floats. The locations of casts pre- and post-2000 are displayed separately. Of the 526 total casts, 326 reached within 200 dbar of the seafloor at their location (solid black circles). Of the 281 casts reaching to $3500 \mathrm{dbar}$ or greater, 203 were taken on the cDrake cruises between 2007 and 2011.

Recent studies have shown that some changes have occurred over time in ACC water properties. However, because there are only a relatively small number of deep-reaching casts in this region, we have chosen to include all casts regardless of the year in which they were taken. To illustrate that the inclusion of data from 

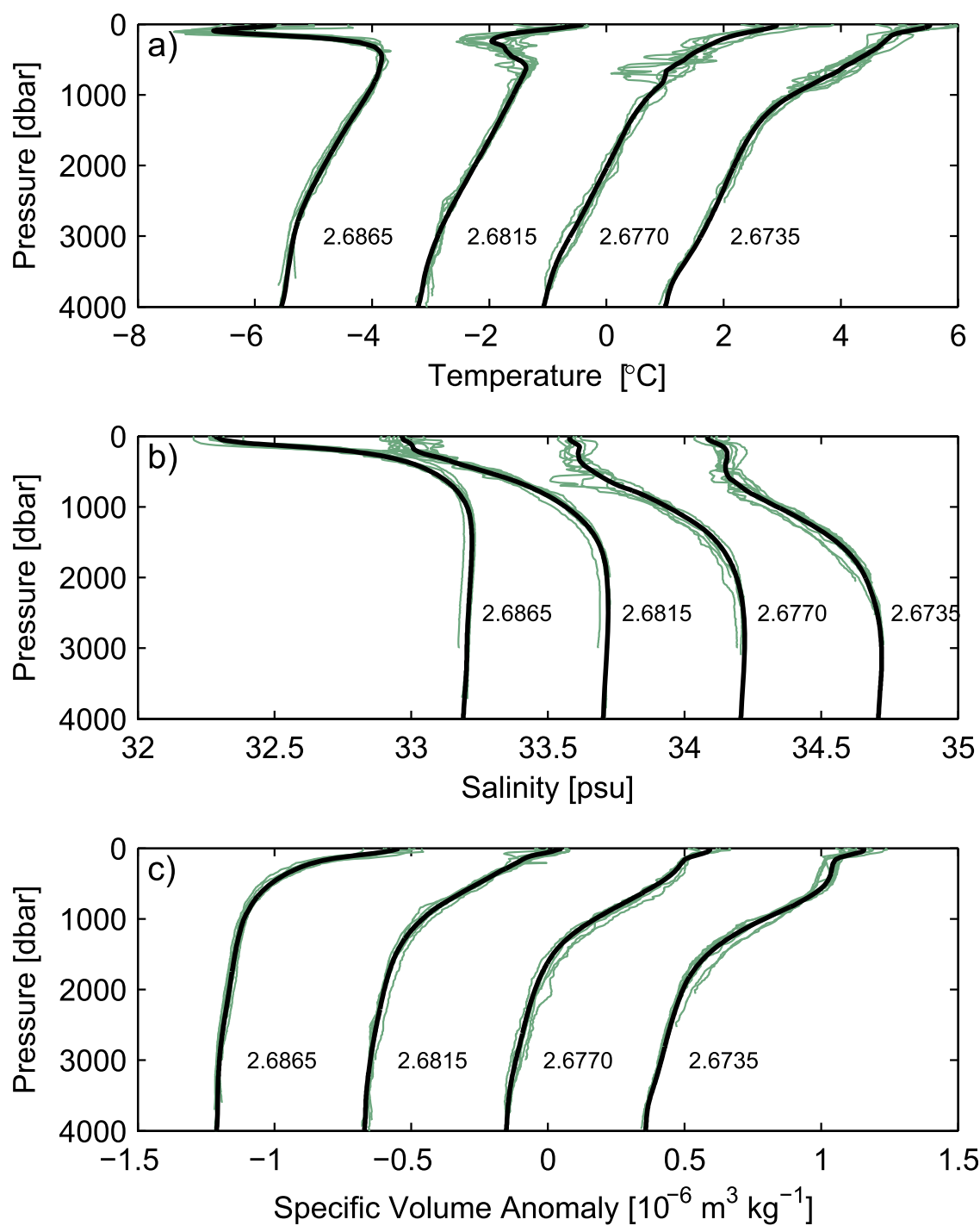

FIG. A3. (a) Four clusters of temperature profiles, each showing all the hydrocast profiles (light green lines) for which the travel time $\tau$ values are within $\pm 0.00025 \mathrm{~s}$ of the values labeled (nominally $0.004 \mathrm{~s}$ apart). The GEM temperature profile at the corresponding $\tau$ is shown by the black line. The rightmost set of profiles has no temperature offset, and the remaining clusters have been offset to the left by increments of $2^{\circ} \mathrm{C}$. (b) As in (a), but for salinity profiles; clusters are offset left by 0.5 psu. (c) As in (a), but for specific volume anomaly $\delta$ profiles; clusters are offset left by $0.5 \times 10^{-6} \mathrm{~m}^{3} \mathrm{~kg}^{-1}$.

multiple decades has little to no effect on our transport calculations, we calculated a second set of GEM lookup tables using only the subset of casts taken between 2000 and 2011. Figure A2 superimposes the fitted spline curves of the cDrake GEMs (black lines) and those created with the data subset (red lines). Small differences between the fits are evident for $T$ and $S$ at the upper three depths. However, these differences have an insignificant effect on $\delta$; for example, the $\delta$ curves at $200 \mathrm{dbar}$ differ by less than $0.2 \times 10^{-7} \mathrm{~m}^{3} \mathrm{~kg}^{-1}$. Consequently, geopotential $\phi$ and baroclinic transport calculated from $\delta$ are also unaffected by these small, interdecadal $T$ and $S$ differences.

Next, we show that the GEM fields capture the dominant vertical structure through the water column. Four clusters of $T, S$, and $\delta$ profiles are shown in Fig. A3. The four $\tau$ groupings, separated nominally by $0.004 \mathrm{~s}$, span nearly the full $\tau$ range of the GEMs. These specific values were selected because multiple deep-reaching casts fell within each $\tau$ cluster. The vertical structure varies substantially between the four clusters, and these differences are captured by the GEM profiles. 

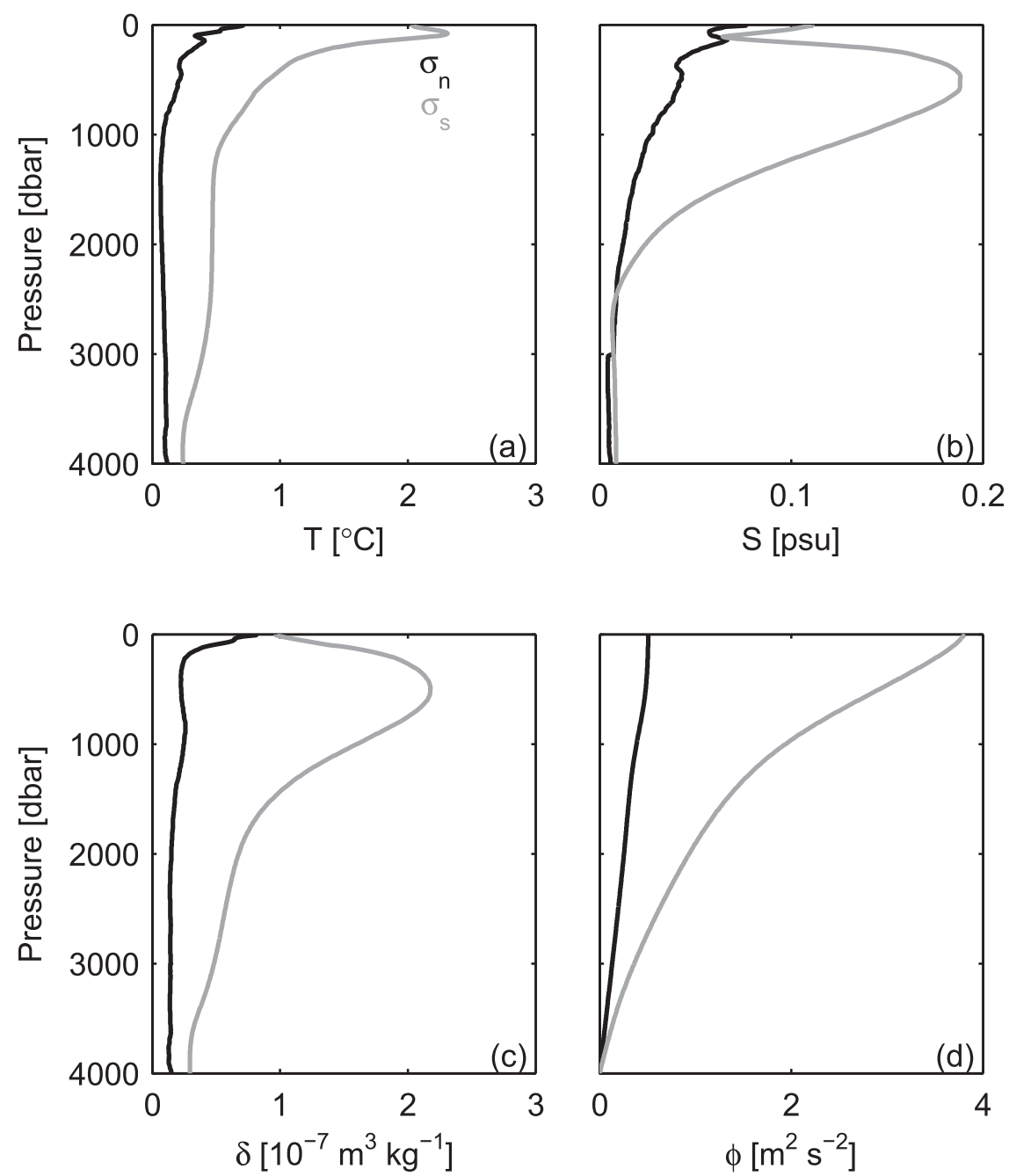

FIG. A4. Comparison of the std dev of the signals $\sigma_{s}$ (gray lines) captured by the GEM splines with those of the scatter $\sigma_{n}$ (black lines) about them determined from the hydrocasts plotted as functions of depth. In general, the signals exceed the noise, except for salinity below $2000 \mathrm{~m}$ where the signal is weak and nearly uniform at each depth.

Comparisons of the signals captured by the GEMs, defined as the total variance of the GEMs spline curve $\left(\sigma_{s}^{2}\right)$ to the scatter about the fitted splines (or noise) defined as the variance of the residuals from the GEMs $\left(\sigma_{n}^{2}\right)$, are shown in Fig. A4. The fraction of variance explained by the GEMs, calculated as $\epsilon=1-\left(\sigma_{n}^{2} / \sigma_{s}^{2}\right)$, was discussed previously in section $2 \mathrm{c}$. We note here that the signals exceed the noise levels everywhere except for $S$ at the deeper levels, where the signals vary weakly (see Fig. A2k).

Together Figs. A2-A4 illustrate that the dominant ACC water properties are well represented by the cDrake GEM lookup tables. Combining the CPIESmeasured $\tau$ with the GEM tables is a robust method for estimating the time-variable ACC baroclinic transport through Drake Passage.

\section{REFERENCES}

Aoki, S., 2002: Coherent sea level response to the Antarctic Oscillation. Geophys. Res. Lett., 29, 1950, doi:10.1029/ 2002 GL015733.

Baker-Yeboah, S., D. R. Watts, and D. A. Byrne, 2009: Measurements of sea surface height variability in the eastern South Atlantic from pressure sensor equipped inverted echo sounders: Baroclinic and barotropic components. J. Atmos. Oceanic Technol., 26, 2593-2609, doi:10.1175/2009JTECHO659.1.

Behnisch, M., A. Macrander, O. Boebel, J.-O. Wolff, and J. Schröter, 2013: Barotropic and deep-referenced baroclinic SSH variability derived from pressure inverted echo sounders (PIES) south of Africa. J. Geophys. Res., 118, 3046-3058, doi:10.1002/jgrc.20195.

Bindoff, N. L., and C. Wunsch, 1992: Comparison of synoptic and climatologically mapped sections in the South Pacific Ocean. J. Climate, 5, 631-645, doi:10.1175/1520-0442(1992)005<0631: COSACM $>2.0 . \mathrm{CO} ; 2$. 
Böning, C. W., A. Dispert, M. Visbeck, S. R. Rintoul, and F. U. Schwazkopf, 2008: The response of the Antarctic Circumpolar Current to recent climate change. Nat. Geosci., 1, 864-869, doi:10.1038/ngeo362.

Chereskin, T. K., K. A. Donohue, D. R. Watts, K. L. Tracey, Y. L. Firing, and A. L. Cutting, 2009: Strong bottom currents and cyclogenesis in Drake Passage. Geophys. Res. Lett., 36, L23602, doi:10.1029/2009GL040940.

— — - and - 2012: cDrake: Dynamics and transport of the Antarctic Circumpolar Current in Drake Passage. Oceanography, 25 (3), 134-135, doi:10.5670/oceanog.2012.86.

Cunningham, S. A., and M. Pavic, 2007: Surface geostrophic currents across the Antarctic Circumpolar Current in Drake Passage from 1992 to 2004. Prog. Oceanogr., 73, 296-310, doi:10.1016/j.pocean.2006.07.010.

__ , S. G. Alderson, and B. A. King, 2003: Transport and variability of the Antarctic Circumpolar Current in Drake Passage. J. Geophys. Res., 108, 8084, doi:10.1029/ 2001JC001147.

Cutting, A. L., 2010: Constituents of sea surface height variability in Drake Passage. M.S. thesis, Department of Physical Oceanography, University of Rhode Island, $68 \mathrm{pp}$.

Donohue, K. A., D. R. Watts, K. L. Tracey, A. D. Greene, and M. Kenelly, 2010: Mapping circulation in the Kuroshio Extension with an array of current and pressure recording inverted echo sounders. J. Atmos. Oceanic Technol., 27, 507-527, doi:10.1175/2009JTECHO686.1.

Ferrari, R., C. Provost, A. Renault, N. Sennéchael, N. Barré, Y.-H. Park, and J. H. Lee, 2012: Circulation in Drake Passage revisited using new current time series and satellite altimetry: 1. The Yaghan Basin. J. Geophys. Res., 117, C12024, doi:10.1029/2012JC008264.

Firing, Y. L., T. K. Chereskin, and M. R. Mazloff, 2011: Vertical structure and transport of the Antarctic Circumpolar Current in Drake Passage from direct velocity observations. J. Geophys. Res., 116, C08015, doi:10.1029/2011JC006999.

— - D. R. Watts, K. L. Tracey, and C. Provost, 2014: Computation of geostrophic streamfunction, its derivatives, and error estimates from an array of CPIES in Drake Passage. J. Atmos. Oceanic Technol., 31, 656-680, doi:10.1175/ JTECH-D-13-00142.1.

Gille, S. T., and C. W. Hughes, 2001: Aliasing of high-frequency variability by altimetry: Evaluation from bottom pressure recorders. Geophys. Res. Lett., 28, 1755-1758, doi:10.1029/ 2000 GL012244.

Griesel, A., M. R. Mazloff, and S. T. Gille, 2012: Mean dynamic topography in the Southern Ocean: Evaluating Antarctic Circumpolar Current transport. J. Geophys. Res., 117, C01020, doi:10.1029/2011JC007573.

Jackett, D. R., and T. J. McDougall, 1997: A neutral density variable for the world's oceans. J. Phys. Oceanogr., 27, 237-263, doi:10.1175/1520-0485(1997)027<0237:ANDVFT>2.0.CO;2.

Koshlyakov, M. N., I. I. Lisina, E. G. Morozov, and R. Y. Tarakanov, 2007: Absolute geostrophic currents in the Drake Passage based on observations in 2003 and 2005. Oceanology, 47, 451563, doi:10.1134/S0001437007040029.

Meijers, A. J. S., N. L. Bindoff, and S. R. Rintoul, 2011a: Estimating the four-dimensional structure of the Southern Ocean using satellite altimetry. J. Atmos. Oceanic Technol., 28, 548-568, doi:10.1175/2010JTECHO790.1.

,-- , and,$- 2011 \mathrm{~b}$ : Frontal movements and property fluxes: Contributions to heat and freshwater trends in the
Southern Ocean. J. Geophys. Res., 116, C08024, doi:10.1029/ 2010JC006832.

Meinen, C. S., and D. R. Watts, 2000: Vertical structure and transport on a transect across the North Atlantic Current near 42 : Time series and mean. J. Geophys. Res., 105, 21869 21 891, doi:10.1029/2000JC900097.

Meredith, M. P., and C. W. Hughes, 2005: On the sampling timescale required to reliably monitor interannual variability in the Antarctic circumpolar transport. Geophys. Res. Lett., 32, L03609, doi:10.1029/2004GL022086.

— , P. L. Woodworth, C. W. Hughes, and V. Stepanov, 2004: Changes in the ocean transport through Drake Passage during the 1980s and 1990s, forced by changes in the Southern Annular Mode. Geophys. Res. Lett., 31, L21305, doi:10.1029/ 2004 GL021169.

, and Coauthors, 2011: Sustained monitoring of the Southern Ocean at Drake Passage: Past achievements and future priorities. Rev. Geophys., 49, RG4005, doi:10.1029/ 2010RG000348.

Munk, W., and D. Cartwright, 1966: Tidal spectroscopy and prediction. Philos. Trans. Roy. Soc. London, 259, 533-581, doi:10.1098/rsta.1966.0024.

Naveira Garabato, A. C., D. P. Stevens, and K. J. Heywood, 2003: Water mass conversion, fluxes, and mixing in the Scotia Sea diagnosed by an inverse model. J. Phys. Oceanogr., 33, 2565-2587, doi:10.1175/1520-0485(2003)033<2565: WMCFAM $>2.0 . \mathrm{CO} ; 2$.

Nowlin, W. D. J., T. Whitworth, and R. D. Pillsbury, 1977: Structure and transport of the Antarctic Circumpolar Current. J. Phys. Oceanogr., 7, 788-802, doi:10.1175/1520-0485(1977)007<0788: SATOTA $>2.0 . \mathrm{CO} ; 2$.

Olbers, D., and K. Lettmann, 2007: Barotropic and baroclinic processes in the transport variability of the Antarctic Circumpolar Current. Ocean Dyn., 57, 559-578, doi:10.1007/ s10236-007-0126-1.

Orsi, A. H., T. Whitworth, and W. D. Nowlin Jr., 1995: On the meridional extent and fronts of the Antarctic Circumpolar Current. Deep-Sea Res. I, 42, 641-673, doi:10.1016/ 0967-0637(95)00021-W.

Renault, A., C. Provost, N. Sennéchael, N. Barré, and A. Kartavtseff, 2011: Two full-depth velocity sections in the Drake Passage in 2006-Transport estimates. DeepSea Res. II, 58, 2572-2591, doi:10.1016/j.dsr2.2011.01.004.

Rintoul, S. R., and Coauthors, 2010: Southern Ocean Observing System (SOOS): Rationale and strategy for sustained observations of the Southern Ocean. Proceedings of OceanObs 09: Sustained Ocean Observations and Information for Society, Vol. 2, J. Hall, D. E. Harrison, and D. Stammer, Eds., European Space Agency Publ. WPP-306, doi:10.5270/ OceanObs09.cwp.74.

Smith, W. H. F., and D. T. Sandwell, 1997: Global sea floor topography from satellite altimetry and ship depth soundings. Science, 277, 1957-1962, doi:10.1126/science.277.5334.1956.

Sokolov, S., and S. R. Rintoul, 2007: Multiple jets of the Antarctic Circumpolar Current south of Australia. J. Phys. Oceanogr., 37, 1394-1412, doi:10.1175/JPO3111.1.

—_, and _ 2009a: Circumpolar structure and distribution of the Antarctic Circumpolar Current fronts: 1. Mean circumpolar paths. J. Geophys. Res., 114, C11018, doi:10.1029/ 2008JC005108.

- and - 2009b: Circumpolar structure and distribution of the Antarctic Circumpolar Current fronts: 2. Variability and 
relationship to sea surface height. J. Geophys. Res., 114, C11019, doi:10.1029/2008JC005248.

Speer, K., S. R. Rintoul, and B. M. Sloyan, 2000: The diabatic Deacon cell. J. Phys. Oceanogr., 30, 3212-3222, doi:10.1175/ 1520-0485(2000)030<3212:TDDC $>2.0 . C O ; 2$.

Sprintall, J., 2003: Seasonal to interannual upper-ocean variability in the Drake Passage. J. Mar. Res., 61, 27-57, doi:10.1357/ 002224003321586408.

Sun, C., and D. R. Watts, 2001: A circumpolar gravest empirical mode for the Southern Ocean hydrography. J. Geophys. Res., 106, 2833-2855, doi:10.1029/2000JC900112.

Swart, S., S. Speich, I. Ansorge, and R. Lutjeharms, 2010: An altimetry-based gravest empirical mode south of Africa: 1. Development and validation. J. Geophys. Res., 115, C03002, doi:10.1029/2009JC005299.

Thompson, D. J., and S. Solomon, 2002: Interpretation of recent Southern Hemisphere climate change. Science, 296, 895-899, doi:10.1126/science.1069270.
Tracey, K. L., K. A. Donohue, D. R. Watts, and T. Chereskin, 2013: cDrake CPIES data report November 2007 to December 2011. Graduate School of Oceanography, University of Rhode Island GSO Tech. Rep. 2008-2, 72 pp. [Available online at http:// digitalcommons.uri.edu/physical_oceanography_techrpts/4.]

Watts, D. R., C. Sun, and S. Rintoul, 2001: A two-dimensional gravest empirical mode determined from hydrographic observations in the Subantarctic Front. J. Phys. Oceanogr., 31, 2186-2209, doi:10.1175/1520-0485(2001)031<2186: ATDGEM $>2.0 . \mathrm{CO} ; 2$.

Whitworth, T., III, 1983: Monitoring the transport of the Antarctic Circumpolar Current at Drake Passage. J. Phys. Oceanogr., 13, 2045-2057, doi:10.1175/1520-0485(1983)013<2045: MTTOTA $>2.0 . \mathrm{CO} ; 2$.

—, and R. G. Peterson, 1985: Volume transport of the Antarctic Circumpolar Current from bottom pressure measurements. J. Phys. Oceanogr., 15, 810-816, doi:10.1175/ 1520-0485(1985)015<0810:VTOTAC $>2.0$. CO;2. 